NBER WORKING PAPER SERIES

\title{
WILLINGNESS TO PAY AND WILLINGNESS TO ACCEPT ARE PROBABLY LESS CORRELATED THAN YOU THINK
}

\author{
Jonathan Chapman \\ Mark Dean \\ Pietro Ortoleva \\ Erik Snowberg \\ Colin Camerer
}

Working Paper 23954

http://www.nber.org/papers/w23954

\author{
NATIONAL BUREAU OF ECONOMIC RESEARCH \\ 1050 Massachusetts Avenue \\ Cambridge, MA 02138 \\ October 2017
}

We thank Douglas Bernheim, Benedetto De Martino, Stefano Della Vigna, Eric Johnson, Graham Loomes, Jan Rivkin, Peter Wakker, Micheal Woodford, and the participants of seminars and conferences for their useful comments and suggestions. Evan Friedman and Khanh Ngoc Han Huynh provided research assistance. Camerer, Ortoleva, and Snowberg gratefully acknowledge the financial support of NSF Grant SMA-1329195. The views expressed herein are those of the authors and do not necessarily reflect the views of the National Bureau of Economic Research.

NBER working papers are circulated for discussion and comment purposes. They have not been peer-reviewed or been subject to the review by the NBER Board of Directors that accompanies official NBER publications.

(C) 2017 by Jonathan Chapman, Mark Dean, Pietro Ortoleva, Erik Snowberg, and Colin Camerer. All rights reserved. Short sections of text, not to exceed two paragraphs, may be quoted without explicit permission provided that full credit, including $\odot$ notice, is given to the source. 
Willingness to Pay and Willingness to Accept are Probably Less Correlated Than You Think Jonathan Chapman, Mark Dean, Pietro Ortoleva, Erik Snowberg, and Colin Camerer NBER Working Paper No. 23954

October 2017

JEL No. C80,D81,D91

\begin{abstract}
$\underline{\text { ABSTRACT }}$
An enormous literature documents that willingness to pay (WTP) is less than willingness to accept (WTA) a monetary amount for an object, a phenomenon called the endowment effect. Using data from an incentivized survey of a representative sample of 3,000 U.S. adults, we add one (probably) surprising additional finding: WTA and WTP for a lottery are, at best, slightly correlated. Across all respondents, the correlation is slightly negative. A meta-study of published experiments with university students shows a correlation of around $0.15--0.2$, consistent with the correlation in our data for high-IQ respondents. While poorly related to each other, WTA and WTP are closely related to different measures of risk aversion, and relatively stable across time. We show that the endowment effect is not related to individual-level measures of loss aversion, counter to Prospect Theory or Stochastic Reference Dependence.

Jonathan Chapman

Division of Social Science

New York University Abu Dhabi

Abu Dhabi

UAE

jchapman@nyu.edu

Mark Dean

Columbia University

$420 \mathrm{~W} 118$ th Street

New York, NY 10027

Mark.Dean@columbia.edu

Pietro Ortoleva

392A Julis Romo Rabinowitz Building

Princeton, NJ 08544

USA

pietro.ortoleva@princeton.edu

Erik Snowberg

Division of Humanities and Social Sciences

MC 228-77

California Institute of Technology

Pasadena, CA 91125

and NBER

snowberg@caltech.edu

Colin Camerer

Department of Economics

California Institute of Technology

Pasadena, CA 91125

camerer@hss.caltech.edu
\end{abstract}




\section{Introduction}

In standard economic theory, willingness to pay (WTP) and willingness to accept (WTA) a monetary amount for an object are the same 1 An enormous experimental and empirical literature finds this is not the case: WTA first-order stochastically dominates WTP, a phenomenon referred to as the endowment effect. $:^{2}$

We add one, probably surprising, finding to this enormous literature: WTA and WTP are, at best, slightly correlated. In a representative sample of the U.S. population, the correlation between WTA and WTP is slightly negative. For subgroups of the population, the correlation is almost always small, typically statistically insignificant, and often negative. This is despite the fact that there is an endowment effect (WTA $>$ WTP) for a majority of participants. Our results come from three large, incentivized, and representative surveys of U.S. adults totaling 3,000 people. Each of these surveys elicits WTA and WTP for two different lottery tickets, which allows us to account for measurement error (using both averaging and ORIV; Gillen et al. 2015). This does not change the results. Nor does excluding respondents that give extreme answers. Nor do a number of other refinements. The only statistically robust correlation (of around 0.2) we observe is for those in the top $5 \%$ of an in-survey IQ test. Additionally, our measures are relatively stable across time, and relate to other features of behavior. Further, we show that our data is incompatible with common ways of modeling the endowment effect.

This paper is unusual in modern behavioral economics as it does not seek to empirically test specific prediction(s). Rather, it documents a set of facts that are difficult to reconcile with existing theories. The approach here is closer to what can be found in disciplines of the natural sciences: an extensive documentation of empirical patterns, leaving the development of novel theories to future research. However, our data is limited to WTA and WTP for lotteries. As we discuss in the Conclusion, there are reasons to believe that, for specific

\footnotetext{
${ }^{1}$ This assumes that the value of the object is small enough that wealth effects are irrelevant.

${ }^{2}$ See Camerer (1995, p. 665), Dhami (2016, p. 217), and Marzilli Ericson and Fuster (2014) for reviews.
} 
physical goods, WTA and WTP may be highly correlated. For example, someone with an allergy to a specific food item is likely to have a both a low WTA and WTP for that good. However, our data suggests that even in those cases correlations are probably lower than expected. Moreover, given the centrality of lottery tickets to the study of risk attitudes and the endowment effect, and of the centrality buying and selling to economic activity, establishing basic facts is important.

Our first survey consisted of 2,000 respondents. This was designed to explore the relationships between a wide variety of behavioral and political measures over time (Camerer et al., 2017a). Our second survey re-interviewed the respondents six months later. Of the original 2,000 respondents, 1,465 completed the second survey. The surprising relationship between WTA and WTP, and a few other factors, encouraged us to run a second study of 1,000 independent respondents (Camerer et al., 2017b). Our large sample size allows us to document relevant facts precisely, even for small sub-groups. Additionally, repeated elicitation from the same people allows us to document that WTA, WTP, and the endowment effect for the two lottery tickets are relatively stable within-person over six months. This reduces concerns that both our results, and others, are driven by noise.

To understand the relationship of our results with the literature, we examine the correlation of WTA and WTP in existing studies containing within-person, incentivized measures. There are three studies that satisfy this criteria (total $N=466$ ); none examine the correlation between WTA and WTP. These studies differ from ours in both elicitation methodology and participant pools. Re-examining their data, we find the correlation between WTA and WTP differs depending on study, but across all three the average is around 0.2 - still small, but higher than in our data. This is, however, consistent with the correlation in our data for those most similar to lab participants - those with high IQs and post-secondary educationsuggesting that the difference between our study and prior work is due to differences in participant populations, rather than methodology. Moreover, it seems that correlations between WTA and WTP are quite meager, even in the lab with university students. 
As our measures of WTA and WTP concern lottery tickets, we investigate the relation between these measures and risk aversion. Each of the seven measures of risk aversion contained in our second study is strongly correlated with WTA or WTP, but rarely both. Moreover the measures correlated with WTA also tend to be highly correlated with each other but not with those correlated with WTP, and vice-versa. This suggests two clusters of risk attitudes, a pattern we explore in detail in Camerer et al. (2017b). For the purposes of the current study, this simply suggests that WTA and WTP each capture something, just not the same thing.

The patterns we discover are difficult to reconcile with existing theories. We derive basic relationships between WTA, WTP, and the endowment effect with risk and loss aversion under three theories - two applications of Prospect Theory to the endowment effect, as well as Stochastic Reference Dependence (Köszegi and Rabin, 2006). These relationships are straightforward to test, and not consistent with the data. Crucially, all three theories predict a positive correlation between loss aversion and the endowment effect. Exploiting two different ways of measuring loss aversion, we find no support for this prediction.

We conclude by discussing a potential path for research. We contend that our findings imply a need to focus on the processes - cognitive, attentional, emotional, and socialunderlying the activities of buying and selling, rather than simply modeling them as gains and losses. This focus is consistent with recent, and growing, evidence from neuroscience: separate neurological processes, and regions of the brain, are involved in these activities. While this literature is still developing, it suggests, together with our findings, the need for more research into these central economic activities.

\section{Design and Data}

Our data come from three incentivized, representative surveys of U.S. adults conducted online by YouGov. YouGov maintains a panel of respondents. It continually recruits new 
people, especially from hard to reach and low socio-economic-status groups. To generate a representative sample, it randomly draws people from various Census Bureau products, and matches them on observables to members of their panel. Differential response rates lead to the over-representation of certain populations. Thus, YouGov provides sample weights to recover estimates that would be obtained from a fully representative sample. We use these weights throughout the paper, including when assessing the percentage of respondents with a certain response or trait. Unweighted results are in Appendix A.

All three surveys were incentivized. That is, respondents were paid based on outcomes associated with their choices. Their choices were used to elicit a large number of attitudes, including WTA and WTP (see Camerer et al. 2017a b, for more details on these other questions). Two of these choices were selected for payment after the respondent completed the entire survey ${ }^{3}$

As our study was run online, WTA and WTP could not be elicited for physical goods. Instead, we elicited these quantities for lottery tickets - although we could not physically give the ticket to respondents. However, the literature has found that the endowment effect is still present for abstract lotteries (see, for example, Isoni et al., 2011). We follow the literature in framing possession of the lottery ticket.

All outcomes were expressed in points. This is an internal YouGov currency used to pay participants. It can be converted to U.S. dollars, or prizes, using the approximate rate of $\$ 0.001$ per point. The average payment to respondents was around $\$ 9$ (9,000 points). The survey took participants between 45 minutes and an hour. This compensation level is quite high for an internet survey, and represents a rate of pay approximately three times the average for YouGov surveys.

The ordering of many of the questions, including WTA and WTP, was randomized. The first survey, which we call Study 1, Wave 1 (W1) contained 2,000 participants and was

\footnotetext{
${ }^{3}$ This is incentive compatible under Expected Utility, but not necessarily under more general risk preferences, where no such mechanism may exist (Karni and Safra, 1987). A growing literature suggests this theoretical concern may not be empirically important (Beattie and Loomes, 1997; Cubitt et al., 1998; Hey and Lee, 2005; Kurata et al., 2009), but there are some exceptions (Freeman et al. 2015).
} 
conducted between March 27 and April 3, 2015. A second wave (Study 1, Wave 2 or W2), recontacted the same population and received 1,465 responses between September 21 and November 23,2015 . The attrition rate of $\sim 25 \%$ is lower than most online surveys. This is due, in part, to YouGov's panel management, and in part to the large incentives we offered. The third survey (Study 2) used an independent sample of 1,000 participants, and was run between March 30 and April 14, 2016. Combining the first wave of the first study with the second study gives us a total population of 3,000 participants, with two observations for approximately half of them.

\section{$2.1 \quad$ Measuring WTA and WTP}

Each survey contained incentivized measures of WTA and WTP for two lottery tickets. This allows a within-subject design. This is necessary for measuring the correlation between WTA and WTP, but unusual in the literature (see Section 5). Using two lottery tickets allows us to correct for measurement error, as discussed in Section 2.2 .4

Each elicitation is performed using a multiple price list (MPL; Holt and Laury, 2002) I $^{5}$ An MPL consists of a table with two columns of outcomes. In each row, the respondent is asked asked to make a choice between the outcomes in the columns. One column contains the same outcome in all rows, while outcomes in the other column vary. In the latter column, the outcome becomes more attractive as one moves down the table. Respondents who understand the question should choose the former option for early rows, and at some point switch to choosing the latter (varying) option. In all rows below that point, the respondent should also choose the latter option ${ }^{6}$ To increase respondents' understanding, the first and the last

\footnotetext{
${ }^{4}$ Approximately half of the subjects received the WTA questions first, and the other half the WTP questions first. In Study 1, Wave 1, these questions appeared in the second and seventh block of questions (out of 11). The same positions were used in Wave 2, but the randomization over the ordering of WTA and WTP was conducted independently of the first wave. In Study 2, these questions appeared in the third and seventh block (out of 12). A qualitative question was asked between the two elicitations of WTA, and also between the two elicitations of WTP.

${ }^{5}$ The MPL is generally considered easier to explain to respondents than, for example, incentivized pricing tasks (see, for example, Cason and Plott, 2014).

${ }^{6}$ Respondents who do not understand the question may switch back and forth between columns multiple
} 
row of the MPL always involved a dominated option - for example, 2,000 points or a lottery that pays 2,000 or 8,000 with equal probability — with the undominated option pre-selected $[7$

The elicitation of WTA had the following form 8

For this question, you are given a lottery ticket that has a $50 \%$ chance of paying you 10,000 points, and a $50 \%$ chance of paying you 0 points. You have two options for this lottery ticket:

- Keep it or

- Sell it for a certain amount of points (for example, 2,000 points).

Respondents were then asked "For each row in the table below, which option would you prefer?" and were presented with an MPL with the option "Keep it" and the option "Sell it for $x$ points", where $x$ changes with the row.

There were two lottery tickets with different payoffs. Table 1 describes the lotteries used in each study. Both waves of Study 1 used the same lotteries. In Study 2, neither lottery included the possibility of receiving 0 . This was included as a robustness check. Note that all lotteries are mean preserving spreads of each other.

For WTP, the same lottery tickets were used, but respondents were instead told:

For this question, you have been given 10,000 points. You will be offered the opportunity to exchange some of these points for a lottery ticket. This lottery ticket has a $50 \%$ chance of paying you 10,000 points, and a $50 \%$ chance of paying 0 points.

For example, if you choose to pay 1,000 points for a lottery ticket, and this question is chosen for payment, you will:

times. However, in our implementation, respondents were not allowed to proceed if there were multiple switches in their choices. They were also not allowed to proceed unless there was a choice in every row. This approach is based on the observation that choices with multiple switches are often thrown out by researchers. This design decision limits our ability to study other types of behaviors that may be indicated by multiple switches, but those are not our focus. In practice, very few instances of multiple switches were observed. This is due to extensive training before the respondent answered their first MPL.

${ }^{7}$ We used the average value of the varying option over the two rows where the respondent's choices switched columns as the value for the lottery ticket. Using the minimum or maximum value does not alter results.

${ }^{8}$ This is taken from our study design documents. These, and screenshots of the surveys, may be found at hss.caltech.edu/ snowberg/wep.html. Screenshots of the WTA and WTP questions may be found in Appendix D. 
Table 1: Lotteries Used

\begin{tabular}{lcc}
\hline \hline & Lottery 1 & Lottery 2 \\
\hline Study 1, Wave 1 \& 2 & $0.5 * 0 \oplus 0.5 * 10,000$ & $0.5 * 2,000 \oplus 0.5 * 8,000$ \\
Study 2 & $0.5 * 1,000 \oplus 0.5 * 9,000$ & $0.5 * 2,000 \oplus 0.5 * 8,000$ \\
\hline \hline
\end{tabular}

- Pay 1,000 points for the lottery ticket;

- Keep 9,000 points for yourself; and

- Earn whatever proceeds you get from the lottery ticket (if any).

Participants were shown an MPL with the options "Keep 10,000 points" and "Buy the lottery ticket for $(10,000-x)$ points and keep the remaining $x$ points", with $x$ varying by row.

In order to identify subjects that chose dominated options without carefully reading the question, an additional design change was made to Study 2. In particular, we included two dominated options at the top and bottom of each MPL. One was pre-selected, consistent with Study 1. The second could be chosen or avoided by respondents ${ }^{9}$ If a respondent chose a dominated option in Study 2, he or she was alerted to this on the next screen. He or she was given the option to go back and change their choice or to continue. For WTA and WTP, $66 \%$ of those alerted to a dominated choice did not change it. We present some results below which exclude those who chose a dominated option.

\section{$2.2 \quad$ Measurement Error}

A common concern with statistically insignificant findings is that they are caused by attenuation bias due to measurement error. Eliciting WTA and WTP for two lotteries for each participant allows us to substantially reduce this concern. We approach this in two ways.

First, we average together the two measures of WTA and WTP in each study. This

\footnotetext{
${ }^{9}$ In particular, in Study 1, the top and bottom row contained the maximum and minimum payment of the lottery. The lottery was pre-selected when the alternative was the minimum of the lottery. When the alternative was the maximum of the lottery, this was pre-selected instead of the lottery. However, in Study 2 , the pre-selected options were in rows with sure payments greater than the maximum payment, and less than the minimum payment, of the lottery.
} 
reduces, but does not eliminate, attenuation due to measurement error. The estimate of the correlation is both biased and inconsistent.

Second, we can use the ORIV technique (Gillen et al., 2015). This adapts an errorsin-variables instrumental variables (IV) approach to our data, and produces consistent estimates of correlations. The main difficulty with a standard IV approach is that each quantity measured is equally valid as a left- or right-hand-side variable. Moreover, for a given righthand-side variable, either observation could be the instrument or the instrumented variable. In essence, ORIV stacks all four possible IV regressions in order to maximize the information in the estimate, and then applies adjustments to get from a regression coefficient to a correlation, and to ensure that standard errors are calculated efficiently.

Formally, with two measures of WTA $\left(\mathrm{WTA}^{*}\right)$ measured with error $\left(\mathrm{WTA}^{a}=\mathrm{WTA}^{*}+\eta^{a}\right.$ and $\mathrm{WTA}^{b}=\mathrm{WTA}^{*}+\eta^{b}$ with $\mathbb{E}\left[\eta^{a}\right]=\mathbb{E}\left[\eta^{b}\right]=\mathbb{E}\left[\eta^{a} \eta^{b}\right]=0$, ), and two of WTP $\left(\mathrm{WTP}^{*}\right)$ measured with error $\left(\mathrm{WTP}^{a}=\mathrm{WTP}^{*}+\nu^{a}\right.$ and $\mathrm{WTP}^{b}=\mathrm{WTP}^{*}+\nu^{b}$ with $\mathbb{E}\left[\nu^{a}\right]=\mathbb{E}\left[\nu^{b}\right]=$ $\left.\mathbb{E}\left[\nu^{a} \nu^{b}\right]=0\right)$, ORIV stacks the values, and estimates:

$$
\begin{gathered}
\left(\begin{array}{c}
\mathrm{WTA}^{a} \\
\mathrm{WTA}^{a} \\
\mathrm{WTA}^{b} \\
\mathrm{WTA}^{b}
\end{array}\right)=\left(\begin{array}{c}
\alpha_{1} \\
\alpha_{2} \\
\alpha_{3} \\
\alpha_{4}
\end{array}\right)+\beta\left(\begin{array}{c}
\mathrm{WTP}^{a} \\
\mathrm{WTP}^{b} \\
\mathrm{WTP}^{a} \\
\mathrm{WTP}^{b}
\end{array}\right)+\varepsilon \\
\text { with instruments } W=\left(\begin{array}{cccc}
\mathrm{WTP}^{b} & 0_{N} & 0_{N} & 0_{N} \\
0_{N} & \mathrm{WTP}^{a} & 0_{N} & 0_{N} \\
0_{N} & 0_{N} & \mathrm{WTP}^{b} & 0_{N} \\
0_{N} & 0_{N} & 0_{N} & \mathrm{WTP}^{a}
\end{array}\right) .
\end{gathered}
$$

This yields regression estimate $\beta^{*}$. The regression coefficient is then transformed into a correlation using

$$
\operatorname{Corr}\left[\mathrm{WTA}^{*}, \mathrm{WTP}^{*}\right]=\hat{\beta}^{*} \sqrt{\frac{\widehat{\widehat{\operatorname{Cov}}}\left[\mathrm{WTP}^{a}, \mathrm{WTP}^{b}\right]}{\widehat{\operatorname{Cov}}\left[\mathrm{WTA}^{a}, \mathrm{WTA}^{b}\right]}}
$$


Table 2: Correlations

\begin{tabular}{ccccccc}
\hline \hline & \multicolumn{3}{c}{ Correlation between WTA and WTP } & \multicolumn{2}{c}{ Correlation within } \\
& Lottery 1 & Lottery 2 & Averages & ORIV & WTA & WTP \\
\hline Study 1, & $-0.06^{*}$ & $-0.06^{*}$ & $-0.08^{* *}$ & $-0.09^{* *}$ & $0.71^{* * *}$ & $0.74^{* * *}$ \\
Wave 1 & $(.037)$ & $(.037)$ & $(.037)$ & $(.044)$ & $(.023)$ & $(.029)$ \\
\hline Study 1, & -0.01 & -0.02 & -0.02 & -0.02 & $0.67^{* * *}$ & $0.79^{* * *}$ \\
Wave 2 & $(.050)$ & $(.049)$ & $(.053)$ & $(.064)$ & $(.033)$ & $(.022)$ \\
\hline Study 2 & $-0.09^{*}$ & -0.06 & -0.09 & -0.11 & $0.70^{* * *}$ & $0.75^{* * *}$ \\
& $(.050)$ & $(.055)$ & $(.057)$ & $(.068)$ & $(.034)$ & $(.044)$ \\
\hline \hline
\end{tabular}

Notes: ${ }^{* * *},{ }^{* *},{ }^{*}$ denote statistical significance at the $1 \%, 5 \%$, and $10 \%$ level, with bootstrapped standard errors from 10,000 simulations in parentheses.

Gillen et al. (2015) shows that this produces consistent estimates of Corr[WTA*, WTP*].

We use a similar stacking of alternative measures in Section 7.2 when regressing WTA, WTP, and the endowment effect on loss aversion, controlling for risk aversion. As each of the three measures we use as controls has multiple elicitations, we create a structure that allows each measure to act as the instrument and the instrumented value, maximizing the efficiency of the estimates.

\section{Results}

We begin by showing the limited correlation between WTA and WTP in our data, in Table 2. Two patterns are worth noting. First, WTA and WTP are not correlated. If there is a relationship, it is negative, although small. That is, observing a high willingness to pay for a lottery ticket conveys very little information about willingness to accept. Second, the two measures of WTA are highly correlated with each other. This is also true of the two measures of WTP. This suggests that these questions are measuring something, just not the same thing. Both of these patterns exist in all three of our surveys.

The middle two columns of Table 2 take steps to reduce concerns about the role of 
measurement error in our results. First, we standardize the two lottery measures of WTA, then average them, and do the same for $\mathrm{WTP}{ }^{10}$ The correlations between the two resultant measures (in the Averages column) grow slightly more negative, consistent with a reduction in the attenuation bias.

Next, we implement the ORIV procedure described in Section 2.2. ORIV produces consistent estimates of correlations, reducing attenuation even further (to zero, in large samples). Once again, the negative correlations grow in magnitude. However, the statistical significance decreases, as ORIV, like all IV techniques, also increases standard errors.

\subsection{The Endowment Effect}

Our data exhibit an endowment effect (WTA > WTP), consistent with existing laboratory data. Across the studies, the average WTA was $90 \%$ of the expected value of the lottery, with a median of $88 \%$, and standard deviation of $37 \%$. The mean WTP is statistically significantly lower at $66 \%$, with a median of $63 \%$, and standard deviation of $33 \%$. The WTP also has a higher proportion of subjects reporting extremely low values - $38 \%$ of subjects reported a WTP of less than half of the expected value, compared to $13 \%$ for WTA. The prevalence of such low values for WTP may concern some readers. Thus, in Section 3.3 and Section 4, we examine various ways to remove outliers.

As shown in Table 3 , the distribution of the endowment effect is consistent across surveys. Approximately $60 \%$ of respondents exhibit an endowment effect, and $10 \%$ exhibit no endowment effect. The final $30 \%$ of respondents exhibit a negative endowment effect. This can be reconciled with prospect theory if respondents are loss loving - which is not uncommon in individual-level studies (see, for example, Sokol-Hessner et al., 2009) These figures are in line with the few previous within-subject studies, see Section 5 .

The existence of a negative endowment effect is not likely to be due solely to measurement

\footnotetext{
${ }^{10}$ Standardizing these measures implies CRRA utility. This is a reasonable assumption given the small differences in stakes between lotteries.

${ }^{11}$ Other studies have found consistent negative endowment effects when physical proximity of a good is counterintuitive: that is, buyers have objects in front of them and sellers do not Knetsch and Wong, 2009).
} 


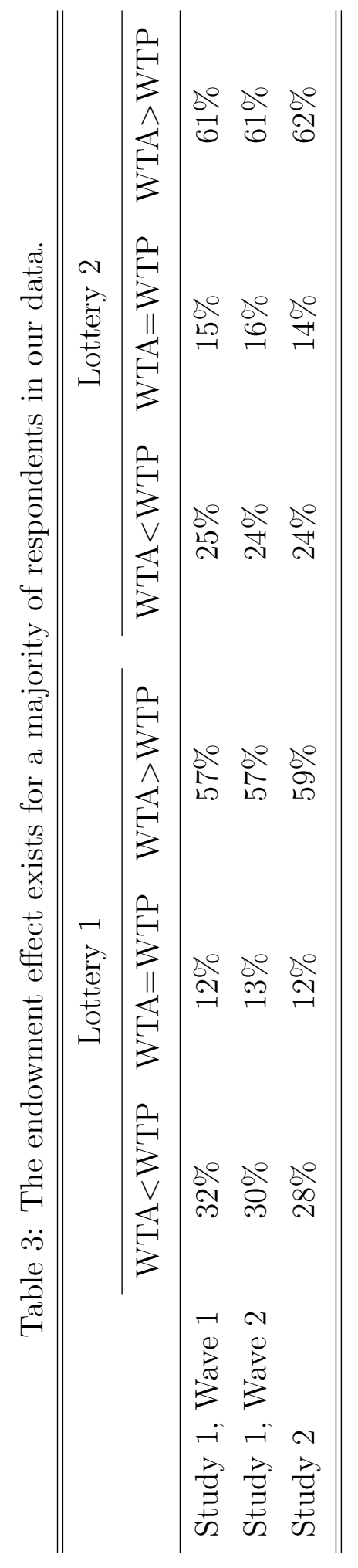


error or random utility. The correlation between the two different measures of the endowment effect (corresponding to each of the two lottery tickets) is 0.75 . This correlation is relatively similar for those with positive and negative endowment effects on a single lottery. To put this another way, of those with a measured endowment effect on a single lottery, there is a $65-75 \%$ chance they have a negative endowment effect on the other lottery. The range depends on the study examined, and how those choosing dominated options are treated. By comparison, those with a positive endowment effect for one lottery ticket had a 70-80\% chance of having a positive endowment effect for the others. Thus, there seems to be only a bit more noise among respondents with a negative endowment effect. ${ }^{2}$

\subsection{Stability Across Time}

A final unique feature of our data is that one of our studies (Study 1) was administered twice to the same respondents, six months apart. This allows us to examine the stability over time of WTA and WTP, as well as any of our other measures. As noted in Section 2, only 1,465 of the original respondents were successfully resurveyed. Using sampling weights allows for representative statistics. However, we cannot rule out the possibility that unobserved factors correlated with WTA and WTP are driving attrition. Thus, it is important to compare the stability of WTA and WTP to the stability of other attitudes.

WTA for the two lotteries are correlated 0.25 and 0.22 across surveys. For WTA, the correlations are 0.29 and $0.26{ }^{13}$ Using ORIV produces correlation estimates of 0.33 for WTA, and 0.34 for WTP. All of these correlations are statistically significantly different from zero, but are not significantly different from each other.

The stability of WTA and WTP are comparable to the stability of other measures of

\footnotetext{
${ }^{12}$ Note that the MPL elicitation method does not allow us to distinguish between those with small positive, small negative, or zero endowment effects. The results in Table 3 assume a valuation that is the midpoint of the certainty equivalents on either side of the MPL switch. Alternative codings produce somewhat different results. The minimum percentage of respondents with negative endowment effects is approximately 10 percentage points below the numbers shown in Table 3 , that is, $15-22 \%$ depending on the lottery and survey.

${ }^{13}$ Recall from Table 1 that both waves employed the same lotteries. Unweighted correlations are 0.24 and 0.23 for WTA, and 0.27 and 0.24 for WTP.
} 
risk preferences. Study 1 contained three other measures of risk aversion. Two were elicited twice, and have ORIV correlations of 0.37 and 0.33. A third was measured only once per survey, and has a correlation of 0.33 across time. This is similar to the stability of measures of risk preferences over about the same amount of time in Caltech undergrads (Gillen et al., 2015) 14 Study 2 also contains two measures of ambiguity aversion (ORIV correlation 0.21 within-subject, across time), time preferences (ORIV correlation 0.33), and amount given in the dictator game (ORIV correlation 0.50).

Three other patterns deserve mention. First, the correlations between WTA in one wave and WTP in the other are nonexistent. This is, perhaps, unsurprising given the lack of correlation within a single study, and the relative stability of WTA and WTP across time. Second, the endowment effect has a (within-participant) correlation of 0.30 across time. Third, we can examine the correlation for WTA and WTP on the subset of people who gave the same valuations in both Wave 1 and Wave 2. For the first lottery, this restricts the sample to 101 participants ${ }^{15}$ The correlation between WTA and WTP for these respondents is $0.10(p=0.30)$ for the first lottery, and $0.01(p=0.90)$ and $0.02(p=0.87)$ for the second lottery in the first and second waves, respectively. For the second lottery, the sample is 122 participants. The correlation between WTA and WTP for these participants is -0.02 $(p=0.84)$ in the second lottery, and $0.04(p=0.70)$ and $0.01(p=0.92)$ in the first lottery in the first and second waves, respectively.

Thus, WTA, WTP, and the endowment effect are as stable as other measures. Once again, this suggests that the WTA and WTP questions are measuring something, just not the same thing.

\footnotetext{
$14($ Gillen et al. 2015$)$ did not elicit WTA and WTP.

15 Almost no one had the same valuations for WTA and WTP for both lotteries.
} 


\subsection{Summary of Basic Findings}

These findings can be summarized, and extended, in a graph. Figure 1 shows average WTA and WTP for all participants in both studies $\sqrt{16}$ We also display a non-parametric fit of the data with $95 \%$ confidence intervals. Finally, the 45-degree line separates those exhibiting positive endowment effects from those exhibiting negative ones.

The previously discussed patterns are immediately apparent. WTA and WTP are poorly correlated. A majority of participants exhibit a positive endowment effect. New patterns emerge from the figure as well. First, to the extent that there is any correlation between WTA and WTP, it is due to participants with above risk-neutral values expressed for WTP. As this describes only $\sim 25 \%$ of participants, this negative relationship is weak, as indicated by the expanding standard errors. Second, there is wide variation in both WTA and WTP.

This wide variation includes participants that give extremely high or low values for WTA and / or WTP. Thus, in the second panel of Figure 1, we remove all subjects that reported either a dominated option, or the next lowest or highest value for any of the four measures of WTA or WTP. The figure displays the same patterns.

The next section considers a number of other subgroups to assess the consistency of our findings across different populations.

\section{Subgroups}

One may believe that a correlation between WTA and WTP would be restored if we focus on specific subgroups: for example, subjects with higher IQ or post-secondary education, or subjects who took their time on the survey, indicating that they were paying attention. We examine the correlation between WTA and WTP for all these subgroups, and some others, in Table 4. Correlations are examined by lottery, for the average of both lotteries, and using ORIV. To maximize statistical power, we combine Study 1, Wave 1 and Study 2. This gives

\footnotetext{
${ }^{16}$ This excludes Wave 2 of Study 1, as these are repeated observations of respondents from Wave 1. All results are shown separately by survey in Appendix B.
} 
Figure 1: WTA and WTP are uncorrelated, even after removing dominated choices.

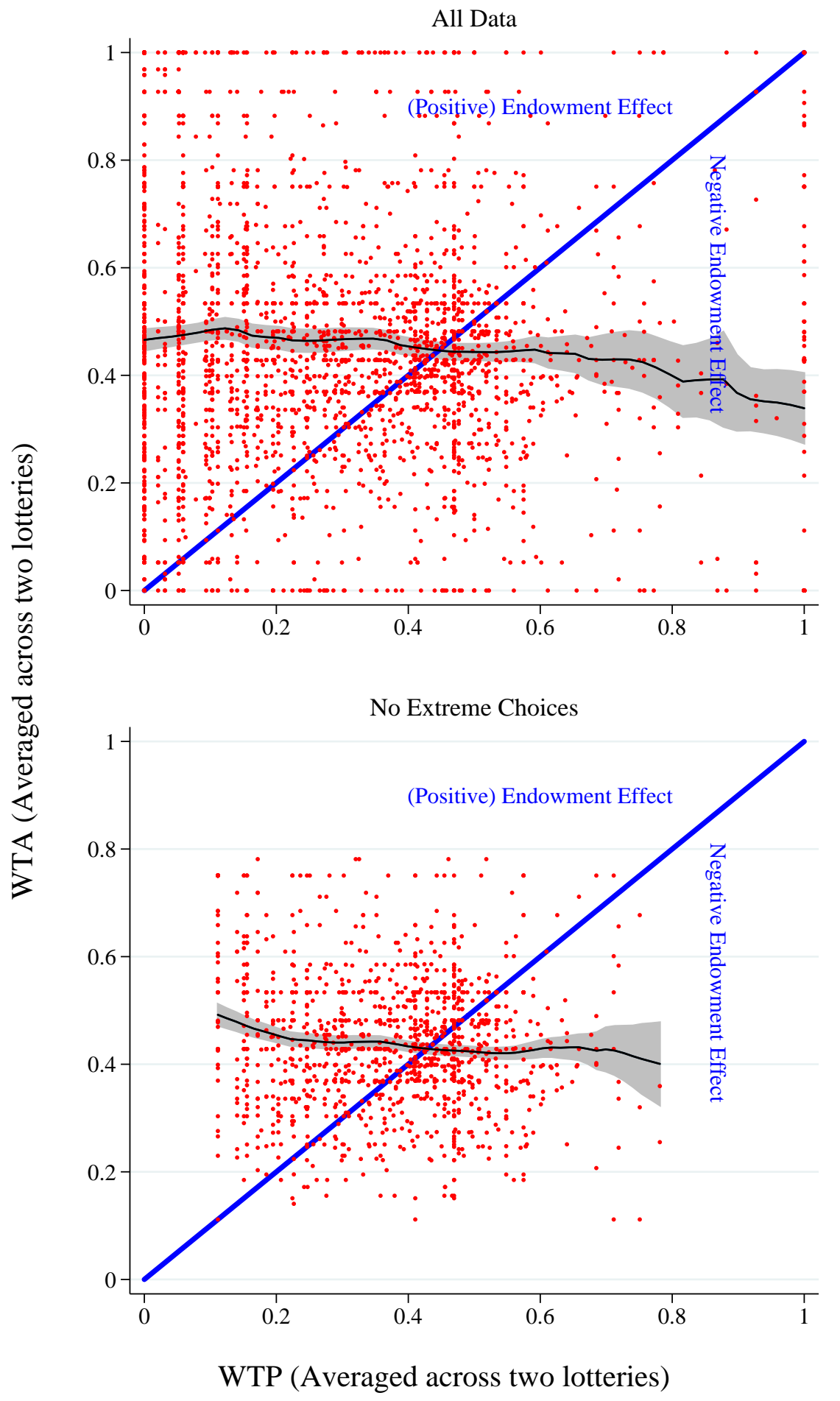


us a total of 3000 independent observations. ${ }^{17}$

Most of the subgroups in the table need no explanation. However, a few do. "Not too fast" removes the $10 \%$ of respondents who completed the WTA and WTP questions in the least amount of time. Similar to our approach in Figure 1, we show three additional ways of removing "extreme" choices in the table: one removes dominated options, one removes respondents whose switching point was just before the first selectable item or just after the last; the second removes subjects if their switching point was in the top three or bottom three rows.

In all subgroups, correlations between WTA and WTP are small in magnitude and / or negative. There is a consistent (small) positive correlation, in the range of $0.1-0.2$, for those with high CRT or IQ scores. In both studies, we administered the Cognitive Reflection Test of Frederick (2005). Around 50\% of respondents got one or more of the three questions correct, representing all those above the median. The top decile answered all three questions correctly. We also administered an in-survey IQ test. This test took a fixed set of six questions from the International Cognitive Ability Resource (ICAR; Condon and Revelle 2014). These six questions were chosen from the matrix and three-dimensional rotation modules such that they were progressively more difficult. Only $5 \%$ of respondents correctly answered all six questions.18 The top decile represents five or more correct answers, and above the median is two or more correct answers.

The only robust positive correlation is for those who answered all six of the IQ questions correctly. Here, the correlation goes as high as 0.28 , although including the next $5 \%$ of respondents in terms of IQ reduces the correlation to around 0.1. In Section 5, we will compare our results to those obtained in the lab - that is, we will examine studies conducted on undergraduate students of elite universities. For that comparison, we isolate those that are college educated ( $2+$ years), younger than 45, and have an IQ plus CRT in the top $20 \%$

\footnotetext{
${ }^{17}$ Wave 2 consists of the same respondents as Wave 1, hence the observations are not independent. For results by survey, see Appendix B.

${ }^{18}$ Consistent with this, none of the authors of this study correctly answered all six questions.
} 
Table 4: Correlations for Subgroups. Data from Study 1, Wave 1 and Study 2

\begin{tabular}{|c|c|c|c|c|c|}
\hline & $\mathrm{N}$ & Lottery 1 & Lottery 2 & Average & ORIV \\
\hline All & 3,000 & $\begin{array}{c}-0.07^{* *} \\
(.030)\end{array}$ & $\begin{array}{c}-0.06^{* *} \\
(.031)\end{array}$ & $\begin{array}{c}-0.08^{* *} \\
(.031)\end{array}$ & $\begin{array}{c}-0.10^{* * *} \\
(.038)\end{array}$ \\
\hline Not Too Fast & 2,700 & $\begin{array}{c}-0.06^{*} \\
(.031)\end{array}$ & $\begin{array}{c}-0.06^{* *} \\
(.031)\end{array}$ & $\begin{array}{c}-0.07^{* *} \\
(.031)\end{array}$ & $\begin{array}{c}-0.09^{* *} \\
(.037)\end{array}$ \\
\hline No Dominated Choices & 2,672 & $\begin{array}{c}-0.07^{* *} \\
(.032)\end{array}$ & $\begin{array}{c}-0.08^{* * *} \\
(.031)\end{array}$ & $\begin{array}{c}-0.09^{* * *} \\
(.032)\end{array}$ & $\begin{array}{c}-0.10^{* * *} \\
(.037)\end{array}$ \\
\hline No Switches in Top or Bottom Two Rows & 1,595 & $\begin{array}{c}-0.11^{* * *} \\
(.043)\end{array}$ & $\begin{array}{c}-0.14^{* * *} \\
(.043)\end{array}$ & $\begin{array}{c}-0.14^{* * *} \\
(.042)\end{array}$ & $\begin{array}{c}-0.19^{* * *} \\
(.051)\end{array}$ \\
\hline No Switches in Top or Bottom Three Rows & 1,028 & $\begin{array}{l}-0.05 \\
(.058)\end{array}$ & $\begin{array}{l}-0.05 \\
(.050)\end{array}$ & $\begin{array}{l}-0.05 \\
(.056)\end{array}$ & $\begin{array}{l}-0.10 \\
(.079)\end{array}$ \\
\hline Question Order: WTA First & 1,501 & $\begin{array}{l}-0.06 \\
(.042)\end{array}$ & $\begin{array}{l}-0.06 \\
(.046)\end{array}$ & $\begin{array}{l}-0.07 \\
(.043)\end{array}$ & $\begin{array}{l}-0.08 \\
(.052)\end{array}$ \\
\hline Question Order: WTP First & 1,499 & $\begin{array}{c}-0.08^{*} \\
(.043)\end{array}$ & $\begin{array}{c}-0.07^{*} \\
(.043)\end{array}$ & $\begin{array}{c}-0.09^{* *} \\
(.044)\end{array}$ & $\begin{array}{c}-0.12^{* *} \\
(.052)\end{array}$ \\
\hline Education: HS or Less & 1,128 & $\begin{array}{c}-0.11^{* *} \\
(.049)\end{array}$ & $\begin{array}{l}-0.05 \\
(.055)\end{array}$ & $\begin{array}{c}-0.11^{* *} \\
(.054)\end{array}$ & $\begin{array}{c}-0.13^{* *} \\
(.066)\end{array}$ \\
\hline Education: Some College & 1,538 & $\begin{array}{l}-0.03 \\
(.039)\end{array}$ & $\begin{array}{c}-0.06^{*} \\
(.037)\end{array}$ & $\begin{array}{l}-0.05 \\
(.039)\end{array}$ & $\begin{array}{l}-0.07 \\
(.046)\end{array}$ \\
\hline Education: Advanced Degree & 334 & $\begin{array}{l}-0.01 \\
(.074)\end{array}$ & $\begin{array}{l}-0.09 \\
(.063)\end{array}$ & $\begin{array}{l}-0.04 \\
(.071)\end{array}$ & $\begin{array}{l}-0.07 \\
(.086)\end{array}$ \\
\hline Income: Above Median & 1,520 & $\begin{array}{l}-0.03 \\
(.037)\end{array}$ & $\begin{array}{l}-0.06 \\
(.041)\end{array}$ & $\begin{array}{l}-0.04 \\
(.038)\end{array}$ & $\begin{array}{l}-0.06 \\
(.046)\end{array}$ \\
\hline Income: Top Quartile & 813 & $\begin{array}{l}-0.01 \\
(.054)\end{array}$ & $\begin{array}{l}-0.01 \\
(.058)\end{array}$ & $\begin{array}{c}0.01 \\
(.053)\end{array}$ & $\begin{array}{c}0.00 \\
(.064)\end{array}$ \\
\hline Income: Top Decile & 399 & $\begin{array}{c}0.06 \\
(.071)\end{array}$ & $\begin{array}{l}-0.04 \\
(.067)\end{array}$ & $\begin{array}{c}0.01 \\
(.073)\end{array}$ & $\begin{array}{c}0.01 \\
(.088)\end{array}$ \\
\hline CRT: Above Median & 1,371 & $\begin{array}{c}0.11^{* * * *} \\
(.042)\end{array}$ & $\begin{array}{c}0.05 \\
(.041)\end{array}$ & $\begin{array}{l}0.09^{* *} \\
(.043)\end{array}$ & $\begin{array}{l}0.10^{* *} \\
(.052)\end{array}$ \\
\hline CRT: Top Decile & 288 & $\begin{array}{c}0.10 \\
(.084)\end{array}$ & $\begin{array}{c}0.11 \\
(.084)\end{array}$ & $\begin{array}{c}0.10 \\
(.085)\end{array}$ & $\begin{array}{l}0.11 \\
(.10)\end{array}$ \\
\hline IQ: Above Median & 1,694 & $\begin{array}{l}-0.03 \\
(.038)\end{array}$ & $\begin{array}{c}-0.06^{*} \\
(.035)\end{array}$ & $\begin{array}{l}-0.05 \\
(.037)\end{array}$ & $\begin{array}{l}-0.07 \\
(.043)\end{array}$ \\
\hline IQ: Top Decile & 337 & $\begin{array}{c}0.10 \\
(.089)\end{array}$ & $\begin{array}{c}0.07 \\
(.075)\end{array}$ & $\begin{array}{c}0.09 \\
(.086)\end{array}$ & $\begin{array}{l}0.10 \\
(.10)\end{array}$ \\
\hline IQ: Top $5 \%$ & 146 & $\begin{array}{c}0.28^{* * *} \\
(.094)\end{array}$ & $\begin{array}{l}0.13 \\
(.10)\end{array}$ & $\begin{array}{l}0.20^{* *} \\
(.098)\end{array}$ & $\begin{array}{l}0.25^{*} \\
(.13)\end{array}$ \\
\hline Age: Youngest Quartile & 611 & $\begin{array}{c}-0.20^{* * *} \\
(.069)\end{array}$ & $\begin{array}{c}-0.23^{* * *} \\
(.062)\end{array}$ & $\begin{array}{c}-0.26^{* * *} \\
(.070)\end{array}$ & $\begin{array}{c}-0.32^{* * *} \\
(.083)\end{array}$ \\
\hline Age: Second Youngest Quartile & 798 & $\begin{array}{l}-0.03 \\
(.056)\end{array}$ & $\begin{array}{l}-0.04 \\
(.056)\end{array}$ & $\begin{array}{l}-0.03 \\
(.053)\end{array}$ & $\begin{array}{l}-0.05 \\
(.063)\end{array}$ \\
\hline Age: Second Oldest Quartile & 783 & $\begin{array}{l}-0.02 \\
(.057)\end{array}$ & $\begin{array}{c}0.04 \\
(.067)\end{array}$ & $\begin{array}{c}0.00 \\
(.062)\end{array}$ & $\begin{array}{c}0.00 \\
(.074)\end{array}$ \\
\hline Age: Oldest Quartile & 808 & $\begin{array}{l}-0.04 \\
(.048)\end{array}$ & $\begin{array}{l}-0.05 \\
(.053)\end{array}$ & $\begin{array}{l}-0.04 \\
(.049)\end{array}$ & $\begin{array}{l}-0.07 \\
(.060)\end{array}$ \\
\hline
\end{tabular}

Notes: ${ }^{* * *},{ }^{* *},{ }^{*}$ denote statistical significance at the $1 \%, 5 \%$, and $10 \%$ level, with bootstrapped standard errors from 10,000 simulations in parentheses. 
Figure 2: In most subgroups, WTP provides no information about WTA.
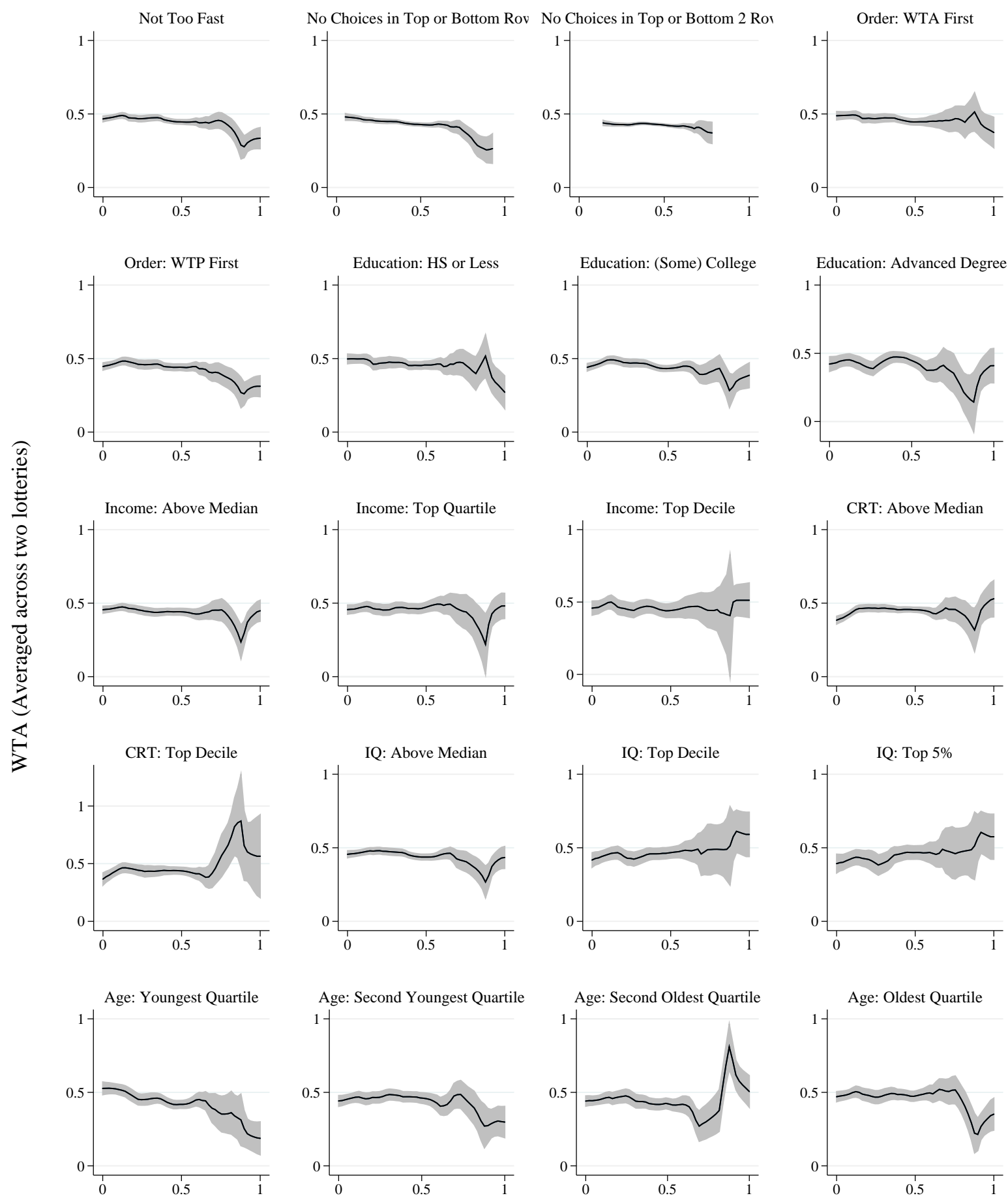

WTP (Averaged across two lotteries) 
$(N=163)$. In this subgroup, the correlation between WTA and WTP is 0.16. ${ }^{19}$

These subgroup results can be illustrated graphically as well. Figure 2 contains 20 panels in the style of Figure 1, showing a non-parametric fit of WTA to WTP. Once again, to the extent that there is any correlation, positive or negative, between WTA and WTP it is for those whose WTP values indicate risk-love. As with Figure 1, this region of the figures contains very few respondents, so any apparent pattern is likely spurious.

\section{$5 \quad$ Prior Studies}

The prior sections lead to a natural question: Why has the limited correlation between WTA and WTP not been documented before? This is likely due to the fact that almost all the studies in the enormous literature on the endowment effect use between-subject designs. In order to examine the correlation between WTA and WTP, one needs a within-subject design. A few studies have collected such data, however we are aware of only one study that examines this correlation: Brown et al. (2017) elicit valuations for two hypothetical annuities, and finds negative correlations between WTA and WTP of -0.11 and -0.15 .

We perform a meta-analysis of the three studies that use within-person incentivized measures of WTA and WTP and have data available $(N=466){ }^{20}$ None of these studies examined the correlation between WTA and WTP. Of these three studies, two used the BDM method (Becker et al., 1964) to elicit WTA and WTP for several lotteries. A third used a median-price auction, repeated six times for each of two lotteries, to elicit WTA and WTP.

\footnotetext{
${ }^{19}$ For those in the top $20 \%$ of IQ + CRT with a college education, the correlation is $0.17(N=702)$; for those in the top decile of IQ + CRT with a college education the correlation is $0.21(N=285)$, and so on.

${ }^{20}$ We searched all papers published in top economics journals. We also consulted the comprehensive annotated bibliography by Peter Wakker (http://people.few.eur.nl/wakker/refs/webrfrncs.docx). This yielded nine studies. Tunçel and Hammitt (2014) conducts a similar search and finds five studies with withinsubject designs - all of which were also found by our search. Three no longer had data available (Harless, 1989: Eisenberger and Weber, 1995, Borges and Knetsch, 1998). Three others we excluded from the metaanalysis: Schmidt and Traub (2009) and Schmidt and Trautmann (2014) use the same data, which contains 23 subjects making choices over 50 lotteries. The range of correlations of WTA and WTP in those lotteries is from -0.67 to 0.86 , with an average of 0.19 . Most of these correlations are statistically insignificant due to the very small sample size. Plott and Zeiler (2005) measures WTA and WTP for lotteries in training rounds, but does not report this data due to concerns about reliability. Although we have similar concerns, for completeness, we include an analysis of this data in Appendix C.
} 
Table 5: The correlation between WTA and WTP for lotteries over gains is limited in prior studies.

\begin{tabular}{|c|c|c|c|c|}
\hline Study & $\begin{array}{l}\text { Group } \\
(\mathrm{N})\end{array}$ & Lottery & Correlation & $\mathrm{WTA}<\mathrm{WTP}$ \\
\hline \multirow{5}{*}{$\begin{array}{l}\text { Isoni et al. } \\
(2011)\end{array}$} & \multirow{5}{*}{$\begin{array}{c}1 \\
(100)\end{array}$} & $0.3 * 1 \oplus 0.7 * 4$ & $\begin{array}{l}0.01 \\
(.10)\end{array}$ & $16 \%$ \\
\hline & & $0.5 * 1.5 \oplus 0.5 * 3.5$ & $\begin{array}{l}0.03 \\
(.10)\end{array}$ & $37 \%$ \\
\hline & & $0.6 * 1 \oplus 0.4 * 3$ & $\begin{array}{c}0.20^{* *} \\
(.10)\end{array}$ & $21 \%$ \\
\hline & & $0.7 * 0.1 \oplus 0.3 * 0.8$ & $\begin{array}{l}0.03 \\
(.10)\end{array}$ & $26 \%$ \\
\hline & & $0.7 * 1 \oplus 0.3 * 5$ & $\begin{array}{l}0.10 \\
(.10)\end{array}$ & $31 \%$ \\
\hline \multirow{7}{*}{$\begin{array}{c}\text { Fehr et al. } \\
(2015)\end{array}$} & \multirow{6}{*}{$\begin{array}{c}1 \\
(95)\end{array}$} & $0.3 * 1 \oplus 0.7 * 8$ & $\begin{array}{l}0.15 \\
(.10)\end{array}$ & $25 \%$ \\
\hline & & $0.5 * 1 \oplus 0.5 * 1.5$ & $\begin{array}{c}0.26^{* *} \\
(.10)\end{array}$ & $35 \%$ \\
\hline & & $0.5 *-3 \oplus 0.5 * 9$ & $\begin{array}{c}0.35^{* * *} \\
(.10)\end{array}$ & $19 \%$ \\
\hline & & $0.6 * 1 \oplus 0.4 * 6$ & $\begin{array}{l}0.20^{*} \\
(.10)\end{array}$ & $24 \%$ \\
\hline & & $0.7 *-0.1 \oplus 0.3 * 0.8$ & $\begin{array}{c}0.22^{* *} \\
(.10)\end{array}$ & $33 \%$ \\
\hline & & $0.7 * 1 \oplus 0.3 * 11$ & $\begin{array}{l}0.11 \\
(.10)\end{array}$ & $32 \%$ \\
\hline & $\begin{array}{c}2 \\
(96)\end{array}$ & $0.5 * 1 \oplus 0.5 * 1.5$ & $\begin{array}{l}0.15 \\
(.10)\end{array}$ & $28 \%$ \\
\hline
\end{tabular}

Notes: ${ }^{* * *},{ }^{* *},{ }^{*}$ denote statistical significance at the $1 \%, 5 \%$, and $10 \%$ level. Correlations with standard errors in parentheses.

The average correlation between WTA and WTP across all three studies is small, but larger than in our study. This difference is probably driven by different samples - representative versus those that come to the lab-rather than differing methodologies.

Table 5 re-analyzes the data from the two studies which use the BDM method. The data from Isoni et al. (2011) suggests little or no correlation between WTA and WTP. On the other 
Table 6: Correlations from repeated measurements of WTA and WTP in (Loomes et al. 2003, $N=175)$.

\begin{tabular}{|c|c|c|c|c|}
\hline & \multicolumn{2}{|c|}{$\begin{array}{c}\text { Lottery } 1 \\
0.2 * 0 \oplus 0.8 * 12\end{array}$} & \multicolumn{2}{|c|}{$\begin{array}{c}\text { Lottery } 2 \\
0.8 * 0 \oplus 0.2 * 12\end{array}$} \\
\hline & Correlation & $\mathrm{WTA}<\mathrm{WTP}$ & Correlation & $\mathrm{WTA}<\mathrm{WTP}$ \\
\hline Round 1 & $\begin{array}{l}0.18^{* *} \\
(.075)\end{array}$ & $38 \%$ & $\begin{array}{c}0.20^{* * *} \\
(.075)\end{array}$ & $32 \%$ \\
\hline Round 2 & $\begin{array}{c}0.22^{* * *} \\
(.074)\end{array}$ & $34 \%$ & $\begin{array}{l}0.14^{*} \\
(.075)\end{array}$ & $30 \%$ \\
\hline Round 3 & $\begin{array}{l}0.28^{* * *} \\
(.073)\end{array}$ & $32 \%$ & $\begin{array}{l}0.28^{* * *} \\
(.073)\end{array}$ & $33 \%$ \\
\hline Round 4 & $\begin{array}{c}0.27^{* * *} \\
(.073)\end{array}$ & $36 \%$ & $\begin{array}{l}0.26^{* * *} \\
(.073)\end{array}$ & $38 \%$ \\
\hline Round 5 & $\begin{array}{l}0.36^{* * *} \\
(.071)\end{array}$ & $33 \%$ & $\begin{array}{l}0.15^{* *} \\
(.075)\end{array}$ & $39 \%$ \\
\hline Round 6 & $\begin{array}{l}0.23^{* * *} \\
(.074)\end{array}$ & $37 \%$ & $\begin{array}{l}0.13^{*} \\
(.075)\end{array}$ & $38 \%$ \\
\hline
\end{tabular}

Notes: ${ }^{* *},{ }^{* *},{ }^{*}$ denote statistical significance at the $1 \%, 5 \%$, and $10 \%$ level. Correlations with standard errors in parentheses.

hand, the data from Fehr et al. (2015) suggests a correlation around 0.2. It is unclear what is driving these differences. Taking an average - weighted by number of participants - of correlations across these studies indicates a correlation of 0.152

While this average correlation is somewhat larger than we observe in our data, it is probably smaller than one would expect. It is also in-line with what we observe, in Section 4. from respondents who are most like those that participate in lab studies. Moreover, the percentage of subjects expressing a negative endowment effect - around 25\% - is quite similar to what we observe in our data (see Table 3). Together with the fact that these two studies use a different elicitation method than we do, this suggests the difference in results is due to our use of a representative participant pool.

Next, we examine the single study that repeatedly elicited WTA and WTP (Loomes ${ }^{21}$ Dropping dominated choices, or replacing them with undominated options, results in similar overall patterns, although the value of particular correlations changes, sometimes substantially. 
et al., 2003). In this study, WTA and WTP for two lotteries were elicited from $N=175$ subjects using a median-price auction. This was done six times, and after each round the price of each lottery was posted. This repetition was used to study whether the endowment effect, and other biases, were reduced by repeated play and learning. The correlations for these two lotteries and negative endowment effect, round by round, are shown in Table 6 . Although there is some variation in the estimated correlations, no two correlations for the same lottery are statistically different from each other, or from the average correlation across both lotteries and all rounds of 0.23 . This suggests, again, that our results are not due to the elicitation method we use. Moreover, the fact that results are fairly stable from round to round suggests that these findings are unlikely to be due to "mistakes."

A final (unpublished) study worth noting elicited WTA and WTP from a non-representative sample of the British population ( $N=1,990$; Carvalho et al., 2017). This study consisted of a subset of the authors here, and used the same setup and lotteries as Study 2. The correlation for both lotteries was 0.10 (s.e. of .027 for both lotteries). This reinforces the contention that the particular (small) correlation observed in different studies is due to the participants, rather than elicitation method. Moreover, across all these different participant pools, the correlation between WTA and WTP is much, much less than 1-and probably much less than one would expect.

\section{Relation with Measures of Risk Aversion}

Thus far, our results suggests that WTA and WTP for lottery tickets are relatively stable and largely independent. As these are values for lotteries, we examine how WTA and WTP relate to seven other measures of risk aversion from Study 2. Each of these measures is highly correlated with WTA or WTP, but rarely both. Moreover, the measures correlated with WTA also tend to be highly correlated with each other, but not with those correlated with WTP, and vice-versa. This reinforces the view that WTA and WTP are capturing 
something, but not the same thing. Following Hershey and Schoemaker (1985) and Sprenger (2015), a plausible reading of these results is that answers to risk preference questions depend on whether a question is implicitly framed as buying or selling a lottery.

The different measures of risk aversion fall into two broad categories: one where the MPL features a fixed lottery, and one where it features a variable lottery. The former category contains four measures that vary in terms of the randomization device in the question and the domain - gains, losses, or both-over which risk is measured ${ }_{22}^{22}$

Urn: This measures the certainty equivalent for a draw from an urn with an equal number of two colors of balls, one representing a large payoff, and the other a zero payoff.

Gain: A lottery where one payoff was a small gain (or zero), and the other a large gain.

Mixed: A lottery where one payoff was a moderate gain, and one was a moderate loss. Participants could choose between these lotteries and sure losses / sure gains.

Loss: A lottery where one payoff was a small loss (or zero), and the other was a large loss. Participants could choose between these lotteries and sure losses.

The second category of measures includes those with a variable lottery. They are:

FM: The monetary amount is fixed $(\mathrm{FM}=$ fixed money $)$, and the participants choose which lotteries (with fixed probabilities but a variable prize) they prefer over this amount.

2L: There is a fixed lottery, and the participants choose which of the variable lotteries (with fixed probabilities) they prefer over this fixed lottery ( $2 \mathrm{~L}=$ two lotteries).

We also administered a qualitative self-assessment of risk attitudes, from Falk et al. (2013). The question reads: "How do you see yourself: are you a person who is generally willing to take risks or do you try to avoid taking risks?", followed by clickable horizontal boxes with the numbers 0 through 10 in them. To the left of 0 , the text reads, "Completely

\footnotetext{
${ }^{22}$ Screenshots and details of the survey design can be found at hss.caltech.edu/ snowberg/wep.html. All questions were elicited twice with different lotteries in order to control for measurement error.
} 





unwilling to take risks," and to the right of 10 the text reads, "Very willing to take risks." All measures of risk aversion are (re-)coded so that a higher value corresponds to more risk aversion. Thus, the expected (and usually observed) sign of the correlation between WTA or WTP and these measures is negative.

An obvious pattern jumps out from the ORIV correlations between these measures, displayed in Table 7; there are two clusters of risk attitudes. These clusters feature high within-cluster correlations, and smaller correlations with measures in the other cluster ${ }^{23}$ Particularly notable is that WTA and WTP are part of different clusters. Loosely speaking, measures in the fixed lottery group are all fairly highly correlated with each other, as are the two variable lottery measures. The fixed lottery measures are generally highly correlated with WTA, but not WTP. ${ }^{24}$ The variable lottery measures show the opposite pattern. The only measure that appears to be (somewhat) correlated across the board is the qualitative measure. Clearly, WTA and WTP are measuring something, just not the same thing.

It is well established that subtle aspects of questions, such as whether the probabilities or payoffs of lotteries differ substantially, can serve as implicit frames (Tversky, 1969). In our context, a plausible explanation for these clusters of risk attitudes, and WTA's and WTP's place in them, may be that the fixed element of the MPL implicitly frames these questions as either buying or selling a lottery citephershey1985pece,sprenger2015endowment. WTA's cluster contains other measures where the lottery option is fixed (on the left-hand side of the MPL), and respondents are asked to assign a price to it. By contrast, in the FM question, the fixed option is an amount of money. This measure is highly correlated with WTP. However, this reading is not perfect: the $2 \mathrm{~L}$ measure contains both a fixed and a variable lottery option

\footnotetext{
${ }^{23}$ The fact that theoretically equivalent measures of risk attitudes produce poorly correlated responses is consistent with a large literature. For recent results from the lab or field, see Berg et al. (2005); Bruner (2009); Crosetto and Filippin (2016); Deck et al. (2010, 2013); Harbaugh et al. (2010); He et al. (2016); Isaac and James (2000); Loomes and Pogrebna (2014); Lönnqvist et al. (2015); Nielsen et al. (2013). See Weber and Johnson (2008) for a summary of the psychology literature on this topic. Gillen et al. (2015) suggest that findings of low correlations between measures of risk attitudes may be due to measurement error-we adopted its techniques to rule this out.

${ }^{24} \mathrm{~A}$ principal components analysis confirms these groupings, and suggests relationships with a broad range of other preference measures, see Camerer et al. (2017b).
} 
and resides in the WTP cluster. Moreover, although risk aversion over losses is firmly in WTA's cluster, it is equally correlated with WTP, but with the opposite sign.

While these results suggest a possible explanation for the small correlation between WTA and WTP_-buying and selling are different processes, an idea we return to in Section 8 they also provide a more direct way to test existing explanations of the endowment effect, which we turn to next.

\section{Relation to Loss-Aversion Based Theories}

The most common explanations of the endowment effect focus on reference-dependent preferences with loss aversion (which we denote by $\lambda$; Kahneman et al., 1990; Tversky and Kahneman, 1991; Köszegi and Rabin, 2006). Do these theories predict anything about the correlation between WTA and WTP? They do not, as most correlations between WTA and WTP can be rationalized by specific correlations between risk and loss aversion. However, these models do make a number of predictions about the relationship between WTA, WTP, the endowment effect, and risk and loss aversion. We test these predictions, and show that they do not match the patterns in our data.

\subsection{Theoretical Predictions}

Throughout what follows, we restrict attention to lotteries like those in our data: they have a high $h$ and low $l$ payoff, each equally likely. Respondents' utility over gains is given by a strictly increasing function $u$. The expected utility of a lottery is denoted by $E U \equiv$ $(u(l)+u(h)) / 2$.

Prospect Theory. Selling a lottery for $x$ gives total value $u(x)-\lambda E U$ under prospect theory ${ }^{25}$ On the other hand, when buying a lottery, a monetary outlay is not usually encoded

\footnotetext{
${ }^{25}$ We do not consider probability weighting here. Adding this does not qualitatively change results. Note that, in our setting, if $\lambda>2 \frac{u(h)}{u(l)+u(h)}$, WTA will exceed the maximum payoff of the lottery, resulting in first
} 
as a loss (Tversky and Kahneman, 1991, p. 1055), leading to:

$$
\mathrm{WTA}_{P T}=u^{-1}(\lambda E U), \quad \text { and } \quad \mathrm{WTP}_{P T}=u^{-1}(E U)
$$

Note that $\mathrm{WTP}_{P T}$ is simply the certainty equivalent of the lottery. Thus, it is decreasing in risk aversion. WTA $_{P T}$ has a similar relationship with risk aversion, but is increasing in loss aversion (controlling for risk aversion). Together, these relationships imply that the endowment effect is increasing in loss aversion (controlling for risk aversion). These predictions are straightforward to test, and we do so in Section 7.2 .

Note that prospect theory makes no prediction about the correlation between WTA and WTP, as this will depend on the joint distribution of utility functions and loss aversion in the population. Fixing $\lambda$ (at, say, 1.5) would yield a strong positive relationship between WTA and WTP - giving rise to the intuition that they should be highly correlated. If, instead, there is little variation in risk aversion, and much more in loss aversion, then WTA and WTP will be uncorrelated. However, in our data, there is substantial variation in both risk aversion and WTP.

Prospect Theory (Alternative). As noted (but generally disregarded) in the literature, it may be the case that respondents encode the payment they make for the lottery as a loss Kahneman et al., 1990; Tversky and Kahneman, 1991). In this case, WTA $_{P T}$ remains the same, but willingness to pay is now given by:

$$
\mathrm{WTP}_{P T}^{\prime}=u^{-1}(E U / \lambda)
$$

which is decreasing in loss aversion. Thus, again, the endowment effect is increasing in loss aversion, controlling for risk aversion.

order stochastically-dominated choices. 
Stochastic Reference Dependence. Under Stochastic Reference Dependence, utility is composed of two parts: reference-free and reference-dependent (Köszegi and Rabin, 2006). The reference-free part is computed using Expected Utility. The reference-dependent part is the difference between the utility obtained and the utility of the reference point, with losses multiplied by loss aversion $\lambda$. As the reference point is stochastic, the reference-dependent part takes the expectation over all possible values of the reference point.

Under this model, keeping a lottery has value $E U+(0 / 2+(u(h)-u(l)) / 2)+(\lambda(u(l)-$ $u(h)) / 2+0 / 2)$. Selling the lottery for $x \in(l, h)$ yields $u(x)+\frac{1}{2}(u(x)-u(l))+\frac{1}{2}(\lambda(u(x)-u(h)))$. Setting these terms equal, we obtain

$$
\mathrm{WTA}_{S R D}=u^{-1}(E U)
$$

This is the same as $\mathrm{WTP}_{P T}$, thus, $\mathrm{WTA}_{S R D}$ is also decreasing in risk aversion.

WTP depends on the respondent's endowment $e$. The utility of not buying the ticket is $u(e)$. The utility for buying the lottery for $y \in(l, h)$ is $(u(e-y+h)+u(e-y+l)) / 2+$ $(u(e-y+h)-u(e)) / 2+\lambda(u(e-y+l)-u(e)) / 2$. Assuming $e=h$, as in our experiment, and setting these expressions equal implies:

$$
\begin{aligned}
u(h)(3+\lambda) & =2 u\left(2 h-\mathrm{WTP}_{S R D}\right)+u\left(h+l-\mathrm{WTP}_{S R D}\right)(1+\lambda) . \\
\Rightarrow \frac{d \mathrm{WTP}_{\mathrm{SRD}}}{d \lambda} & =\frac{u\left(h+l-\mathrm{WTP}_{S R D}\right)-u(h)}{2 u^{\prime}\left(2 h-\mathrm{WTP}_{S R D}\right)+u^{\prime}\left(h+l-\mathrm{WTP}_{S R D}\right)} .
\end{aligned}
$$

As $h>\mathrm{WTP}_{S R D}>l, \mathrm{WTP}_{S R D}$ is decreasing in loss aversion $\lambda$. Standard intuitions about risk aversion give that $\mathrm{WTP}_{S R D}$ is decreasing in the curvature of $u$.

\subsection{Tests}

The theories summarized above make predictions about the relationship between WTA, WTP, the endowment effect, and risk and loss aversion. These predictions are summarized 
Table 8: Relationships between WTA, WTP, and the Endowment Effect, and loss and risk aversion.

\begin{tabular}{|c|c|c|c|}
\hline $\begin{array}{l}\text { Dependent } \\
\text { Variable: }\end{array}$ & WTA & WTP & $\begin{array}{l}\text { Endowment } \\
\text { Effect }\end{array}$ \\
\hline \multicolumn{4}{|c|}{$\begin{array}{l}\text { Panel A: Theoretical Relationships with Loss Aversion } \\
\text { (Controlling for negative relationship with Risk Aversion) }\end{array}$} \\
\hline $\begin{array}{l}\text { Prospect Theory } \\
\text { (Standard) }\end{array}$ & + & 0 & + \\
\hline $\begin{array}{l}\text { Prospect Theory } \\
\text { (Alternative) }\end{array}$ & + & - & + \\
\hline $\begin{array}{l}\text { Stochastic Reference } \\
\text { Dependence }\end{array}$ & 0 & - & + \\
\hline \multicolumn{4}{|c|}{ Panel B: Study 1, Wave 1} \\
\hline Loss Aversion & $\begin{array}{l}-0.04 \\
(.033)\end{array}$ & $\begin{array}{l}-0.03 \\
(.030)\end{array}$ & $\begin{array}{c}0.00 \\
(.030)\end{array}$ \\
\hline Risk Aversion & $\begin{array}{l}-0.73^{* * *} \\
(.093)\end{array}$ & $\begin{aligned}- & 0.38^{* * *} \\
& (.10)\end{aligned}$ & $\begin{aligned}-0.28^{* * *} \\
(.11)\end{aligned}$ \\
\hline \multicolumn{4}{|c|}{ Panel C: Study 2 (IV Specification) } \\
\hline $\begin{array}{l}\text { Loss Aversion } \\
\text { (Mixed) }\end{array}$ & $\begin{array}{c}-0.41^{* * *} \\
(.098)\end{array}$ & $\begin{array}{c}0.05 \\
(.088)\end{array}$ & $\begin{array}{c}-0.33^{* * *} \\
(.091)\end{array}$ \\
\hline $\begin{array}{l}\text { Risk Aversion } \\
\text { (Gains) }\end{array}$ & $\begin{array}{c}-0.51^{* * *} \\
(.078)\end{array}$ & $\begin{array}{c}-0.12^{*} \\
(.062)\end{array}$ & $\begin{array}{c}-0.30^{* * *} \\
(.067)\end{array}$ \\
\hline $\begin{array}{l}\text { Risk Aversion } \\
\text { (Losses) }\end{array}$ & $\begin{array}{c}0.20^{* * *} \\
(.073)\end{array}$ & $\begin{array}{c}0.33^{* * *} \\
(.10)\end{array}$ & $\begin{array}{l}-0.07 \\
(.083)\end{array}$ \\
\hline
\end{tabular}

Notes: ${ }^{* * *},{ }^{* *},{ }^{*}$ denote statistical significance at the $1 \%, 5 \%$, and $10 \%$ level. Standard errors in parentheses. Panel C displays bootstrapped standard errors from 10,000 simulations.

in Panel A of Table 8.

Our data provide two ways to test these predictions, as each study used a different method to elicit loss aversion in risky choice ${ }^{26}$ In Study 1, we used the Dynamically Opti-

\footnotetext{
${ }^{26}$ Some readers have suggested that the endowment effect is instead governed by a different loss-aversion parameter. However, this makes for a theory with no predictive power in our data, because there are as many parameters as there are choices. We are aware of two unpublished studies that attempt to study the relationship between the endowment effect and loss aversion. Gächter et al. (2007) relates the endowment effect to a measure similar to our "Mixed" measure. Its results are similar to the unconditional correlation between that measure and the endowment effect in our data, and we find that the endowment effect is unrelated to loss aversion. Dean and Ortoleva (2016) finds a correlation between loss aversion and the
} 
mized Sequential Experimentation (DOSE) procedure of Chapman et al. (2017) to elicit risk and loss aversion parameters. This method optimally selects a series of questions for each respondent in order to maximize the information about a CRRA risk parameter and a loss aversion parameter. Each of these questions is a binary choice between a lottery and a sure amount, and is selected based on past answers in order to optimally identify the parameters of this model with only 20 questions. The estimated parameters from this method are more stable across time (between Wave 1 and Wave 2) than WTA, WTP, risk aversion, ambiguity aversion, and so on ${ }^{27}$

These DOSE-estimated parameters are used to test theoretical predictions about WTA, WTP, and the endowment effect in Panel B of Table 8, WTA and WTP are significantly negatively related to risk aversion, as predicted by all three theories. However, counter to all three theories, all three quantities are unrelated to loss aversion.

As noted in Section 6, Study 2 also contained three measures that can be used together to identify loss aversion. To do so, we include the certainty equivalents for all three measures in a regression. The certainty equivalent for a lottery over gains identifies risk aversion; the certainty equivalent for a lottery over losses identifies risk aversion over loses. Thus, by controlling for both of these quantities, the residual variation in the certainty equivalent for a lottery over gains and losses encodes loss aversion. As each of these quantities is measured with error, we instrument all of them, as recommended by Gillen et al. (2015), through a "stacked" regression, as described in Section 2.2 $\left.\right|^{28}$ Here again, our results are not compatible with the predictions of any of the three theories.

endowment effect in lab data from an elite university. However, their approach differs from ours in a number of ways: they measure loss aversion parametrically, without accounting for measurement error, and their loss aversion questions are framed in terms of WTA, which may have important effects.

${ }^{27}$ The cross-time correlation in the risk aversion parameter elicited via DOSE is 0.44 , and the cross-time correlation in loss aversion is 0.40 . This compares favorably with the cross-time correlations for the other risk preference measures mentioned in Section 3.2 .

${ }^{28}$ One could also fit a parametric model using these three certainty equivalents. However, this would exclude respondents whose choices over these six questions (three quantities, each asked twice) appeared to violate first-order stochastic dominance. As this is expected, and does, happen with some frequency due to measurement error, the specification in Panel $\mathrm{C}$ allows us to retain all data. Note that all three of the variables in Panel $\mathrm{C}$ have been re-coded, as described in Section 6, so that higher values imply more risk and loss aversion. 


\section{Discussion and Conclusion}

Using three large, representative, incentivized surveys of U.S. adults, as well as data from previous studies, we document a number of facts about WTA, WTP, and the endowment effect. First, WTA and WTP appear to be, at best, slightly correlated. This is true across a large number of demographic subgroups - except those with the highest IQ and education, where the correlation remains small. Second, the majority of people exhibits the endowment effect, although there exists a substantial minority that exhibits a negative endowment effect $(\mathrm{WTA}<\mathrm{WTP})$. Third, WTA, WTP, and the endowment effect are as stable across time as other measures of risk and time preferences. Fourth, WTA and WTP are correlated with other measures of risk preferences in a sensible way, depending on whether the fixed option in an MPL is a monetary amount or a lottery, suggesting that whether a question is framed as "buying" or "selling" is important. Fifth, our results are similar to existing studies that contain within-person measures of WTA and WTP. Sixth, while these patterns are compatible with modeling the endowment effect using Prospect Theory or Stochastic Reference Dependence, the central predictions of those theories about the relationships between WTA, WTP, the endowment effect and risk and loss aversion are not supported in our data.

None of these results imply that a given person's WTA and WTP should be independent across different goods or lotteries ${ }^{29}$ That is, we expect that people who have a much higher WTP for good $A$ than good $B$ would tend to maintain that ordering in WTA. For example, most people are likely to have a much higher WTA and WTP for a Ferrari than a used bicycle. As mentioned in the Introduction, there are likely to be many cases where WTA and WTP would be highly correlated, even for the same object. This would mainly occur when some people have no or low value for an object, while others value it highly. For example, a ticket for a Broadway show will have a much higher WTA and WTP for someone who lives in New York City than someone who lives in Timbuktu.

\footnotetext{
${ }^{29}$ Indeed, in our data, WTA, WTP, and the endowment effect are highly correlated within person across lotteries and time.
} 
Our results point to the need for a different approach to modeling the endowment effect: Instead of linking buying and selling with losses and gains, we believe the focus should instead be on the processes - cognitive, attentional, emotional, and social - connected to buying and selling. As an example, one may imagine that those who exhibit an endowment effect care a lot about getting the best deal when both buying and selling, that is, they do not want to be a "sucker." On the other hand, those who exhibit a negative endowment effect have a lower WTA and a higher WTP to "close the deal." 30 These are just intuitive examples of the potential complex forces at play.

The presence of different processes could be modeled with different utility functions for buying and selling, rather than for gains and losses. These functions need not have any particular relationship within a given person, making this approach trivially compatible with any correlation between WTA and WTP. This approach is also compatible with the fact that WTA and WTP are each related to different features of risk aversion, as shown in Section 6. These two utility functions can serve as the extremes that define an incomplete preference relation - connecting with the existing approach to modeling the endowment effect that does not rely on loss aversion 31

An important advantage of focusing on the processes involved in buying and selling is the ability to link with substantial evidence from neuroscience of different mechanistic processes (in the brain) governing these two actions. An early fMRI study found distinct activity in the medial prefrontal cortex (mPFC) when making a buying decision at a low price and (more weakly) a selling decision at a high price (Knutson et al., 2008). This region encodes abstract integrated types of value, which is consistent with a value for being relatively confident in

\footnotetext{
${ }^{30}$ People often overbid private values in second-price auctions, especially when they have high valuations for the object on auction (Cooper and Fang, 2008). Participants in these auctions often say they entered a high bid to "Be sure they win." A similar psychology may generate negative endowment effects.

${ }^{31}$ Incomplete preferences build on the idea that a respondent may not know her exact value for an objecther preferences are incomplete - and only "moves away" from her current situation if she knows that the alternative is better. It is easy to show how this generates the endowment effect. For example, if the agent's value for the object is between $\$ 5$ and $\$ 10$, then she would not buy it for more than $\$ 5$, and not sell for less than $\$ 10$. See Masatlioglu and Ok (2005, 2014), and also Bewley (1986) and Ortoleva (2010). This model is trivially compatible with any correlation between WTA and WTP. It is only incompatible with the fact that a substantial minority of respondents exhibits a negative endowment effect.
} 
getting a good deal. Further, the size of the endowment effect was correlated with the amount of differential activity in the insula during selling versus buying. This indicates that selling and buying decisions are processed differently in the brain, and the difference is likely associated with more uncertainty or emotional discomfort during selling (as those are common functions of the insula). Another study found increased activity in the amygdala and caudate nucleus during selling; the former is consistent with enhanced emotional salience during selling (Weber et al., 2007). Finally, there is evidence that WTP is processed by the the medial orbitofrontal cortex (mOFC), while WTA is processed by a more lateral portion of the OFC (the lOFC, see De Martino et al., 2009). These studies do not form a simple, integrated neuro-psychological picture, but all show differences in neural processing during buying versus selling.

This discussion is, of course, far from suggesting a particular formal model. This is in keeping with the goal of this paper as outlined in the Introduction: to document facts about WTA, WTP, and the endowment effect, and to explore how existing models (fail to) account for them. We leave the development of novel models for future research. However, we believe our results suggest the need to deepen our knowledge of the processes involved with buying and selling. These actions are at the center of economic activity. And surprisingly, they are, as of yet, not fully understood by economists. 


\section{References}

Beattie, Jane and Graham Loomes, "The Impact of Incentives upon Risky Choice Experiments," Journal of Risk and Uncertainty, March 1997, 14 (2), 155-68.

Becker, Gordon M., Morris H. DeGroot, and Jacob Marschak, "Measuring Utility by a Single-Response Sequential Method," Behavioral Science, 1964, 9 (3), 226-232.

Berg, Joyce, John Dickhaut, and Kevin McCabe, "Risk Preference Instability Across Institutions: A Dilemma," Proceedings of the National Academy of Sciences of the United States of America, 2005, 102 (11), 4209-4214.

Bewley, Truman F, "Knightian Decision Theory: Part I," Cowles Foundation discussion paper, 1986, $80 \%$.

Borges, Bernhard F.J. and Jack L. Knetsch, "Tests of Market Outcomes with Asymmetric Valuations of Gains and Losses: Smaller Gains, Fewer Trades, and Less Value," Journal of Economic Behavior \& Organization, 1998, 33 (2), 185-193.

Brown, Jeffrey R. Arie Kapteyn, Erzo F.P. Luttmer, and Olivia S. Mitchell, "Cognitive Constraints on Valuing Annuities," Journal of the European Economic Association, 2017, 15 (2), 429-462.

Bruner, David M., "Changing the Probability versus Changing the Reward," Experimental Economics, 2009, 12 (4), 367-385.

Camerer, Colin F., "Individual Decision Making," in John H. Kagel and Alvin E. Roth, eds., Handbook of Experimental Economics, Vol. 2, Princeton, NJ: Princeton University Press, 1995, pp. 587-703.

_, Jonathan Chapman, Pietro Ortoleva, and Erik Snowberg, "Time Stability of Econographics," 2017. Caltech, mimeo.

_ , Mark Dean, Jonathan Chapman, Pietro Ortoleva, and Erik Snowberg, "Econographics: Factors of Economic Decision Making," 2017. Caltech, mimeo.

Carvalho, Leandro, Pietro Ortoleva, Francisco Perez-Arce, and Erik Snowberg, "Education and Preferences," 2017. University of Southern California, mimeo.

Cason, Timothy N. and Charles R. Plott, "Misconceptions and Game Form Recognition: Challenges to Theories of Revealed Preference and Framing," Journal of Political Economy, 2014, 122 (6), 1235-1270.

Chapman, Jonathan, Erik Snowberg, Stephanie Wang, and Colin F. Camerer, "Dynamically Optimized Sequential Experimentation (DOSE) for for Estimating Economic Preference Parameters," 2017. California Insitute of Technology, mimeo.

Condon, David M. and William Revelle, "The International Cognitive Ability Resource: Development and Initial Validation of a Public-domain Measure," Intelligence, $2014,43(2), 52-64$. 
Cooper, David J. and Hanming Fang, "Understanding Overbidding in Second Price Auctions: An Experimental Study," The Economic Journal, 2008, 118 (532), 1572-1595.

Crosetto, Paolo and Antonio Filippin, "A Theoretical and Experimental Appraisal of Four Risk Elicitation Methods," Experimental Economics, 2016, 19 (3), 613-641.

Cubitt, Robin, Chris Starmer, and Robert Sugden, "On the Validity of the Random Lottery Incentive System," Experimental Economics, 1998, 1 (2), 115-131.

De Martino, Benedetto, Dharshan Kumaran, Beatrice Holt, and Raymond J Dolan, "The Neurobiology of Reference-Dependent Value Computation," The Journal of Neuroscience, 2009, 29 (12), 3833-3842.

Dean, Mark and Pietro Ortoleva, "Is it All Connected? A Testing Ground for Unified Theories of Behavioral Economics Phenomena," 2016. Columbia University, mimeo.

Deck, Cary, Jungmin Lee, and Javier A. Reyes, "Personality and the Consistency of Risk Taking Behavior: Experimental Evidence," 2010. University of Arkansas, mimeo.

_, _, Javier Reyes, and Christopher Rosen, "A Failed Attempt to Explain within subject Variation in Risk Taking Behavior using domain specific risk attitudes," Journal of Economic Behavior \&3 Organization, 2013, 87, 1-24.

Dhami, Sanjit, The Foundations of Behavioral Economic Analysis, Oxford University Press, 2016.

Eisenberger, Roselies and Martin Weber, "Willingness-to-pay and Willingness-toaccept for Risky and Ambiguous Lotteries," Journal of Risk and Uncertainty, 1995, 10 (3), 223-233.

Falk, Armin, Anke Becker, Thomas Dohmen, David Huffman, and Uwe Sunde, "An Experimentally Validated Preference Survey Module," 2013. University of Bonn, mimeo.

Fehr, Dietmar, Rustamdjan Hakimov, and Dorothea Kübler, "The Willingness to Pay-Willingness to Accept Gap: A Failed Replication of Plott and Zeiler," European Economic Review, 2015, 78, 120-128.

Frederick, Shane, "Cognitive Reflection and Decision Making," The Journal of Economic Perspectives, 2005, 19 (4), 25-42.

Freeman, David, Yoram Halevy, and Terri Kneeland, "Eliciting Risk Preferences using Choice Lists," 2015. University of British Columbia, mimeo.

Gächter, Simon, Eric J. Johnson, and Andreas Herrmann, "Individual-level Loss Aversion in Riskless and Risky Choices," IZA Discussion Paper \# 2961, 2007.

Gillen, Ben, Erik Snowberg, and Leeat Yariv, "Experimenting with Measurement Error: Techniques and Applications from the Caltech Cohort Study," 2015. California Institute of Technology, mimeo. 
Harbaugh, William T., Kate Krause, and Lise Vesterlund, "The Fourfold Pattern of Risk Attitudes in Choice and Pricing Tasks," Economic Journal, 2010, 120 (6), 595-611.

Harless, David W., "More Laboratory Evidence on the Disparity between Willingness to Pay and Compensation Demanded," Journal of Economic Behavior 65 Organization, 1989, 11 (3), 359-379.

He, Pan, Marcella Veronesi, and Stefanie Engel, "Consistency of Risk Preference Measures and the Role of Ambiguity: An Artefactual Field Experiment from China," 2016. ETH Zurich, mimeo.

Hershey, John C. and Paul J.H. Schoemaker, "Probability Versus Certainty Equivalence Methods in Utility Measurement: Are they Equivalent?," Management Science, 1985, 31 (10), 1213-1231.

Hey, John and Jinkwon Lee, "Do Subjects Separate (or Are They Sophisticated)?," Experimental Economics, September 2005, 8 (3), 233-265.

Holt, Charles A. and Susan K. Laury, "Risk Aversion and Incentive Effects," American Economic Review, 2002, 92 (5), 1644-1655.

Isaac, R Mark and Duncan James, "Just who are you Calling Risk Averse?," Journal of Risk and Uncertainty, 2000, 20 (2), 177-187.

Isoni, Andrea, Graham Loomes, and Robert Sugden, "The Willingness to PayWillingness to Accept Gap, the 'Endowment Effect,' Subject Misconceptions, and Experimental Procedures for Eliciting Valuations: Comment," American Economic Review, 2011, 101 (2), 991-1011.

Kahneman, Daniel, Jack L. Knetsch, and Richard H. Thaler, "Experimental Tests of the Endowment Effect and the Coase Theorem," Journal of Political Economy, 1990, 98 (6), 1325-1348.

Karni, Edi and Zvi Safra, "'Preference Reversal' and the Observability of Preferences by Experimental Methods," Econometrica, 1987, 55 (3), 675-685.

Knetsch, Jack L. and Wei-Kang Wong, "The Endowment Effect and the Reference State: Evidence and Manipulations," Journal of Economic Behavior E Organization, 2009, 71 (2), 407-413.

Knutson, Brian, G.Ẽlliott Wimmer, Scott Rick, Nick G Hollon, Drazen Prelec, and George Loewenstein, "Neural Antecedents of the Endowment Effect," Neuron, 2008, 58 (5), 814-822.

Köszegi, Botond and Matthew Rabin, "A Model of Reference-Dependent Preferences," Quarterly Journal of Economics, 2006, 121 (4), 1133-1165.

Kurata, Hiroshi, Hiroshi Izawa, and Makoto Okamura, "Non-Expected Utility Maximizers Behave as if Expected Utility Maximizers: An Experimental Test," Journal of Socio-Economics, 2009, 38 (4), 622-629. 
Lönnqvist, Jan-Erik, Markku Verkasalo, Gari Walkowitz, and Philipp C Wichardt, "Measuring Individual Risk Attitudes in the Lab: Task or Ask? An Empirical Comparison," Journal of Economic Behavior \&3 Organization, 2015, 119, 254-266.

Loomes, Graham and Ganna Pogrebna, "Measuring Individual Risk Attitudes when Preferences are Imprecise," The Economic Journal, 2014, 124 (576), 569-593.

_, Chris Starmer, and Robert Sugden, "Do Anomalies Disappear in Repeated Markets?," The Economic Journal, 2003, 113 (486), C153-C166.

Marzilli Ericson, Keith M. and Andreas Fuster, "The Endowment Effect," Annual Review of Economics, 2014, 6 (1), 555-579.

Masatlioglu, Yusufcan and Efe A Ok, "Rational Choice with status quo bias," Journal of Economic Theory, 2005, 121, 1-29.

- and Efe A. Ok, "A Canonical Choice Model with Initial Endowment," Review of Economic Studies, 2014, 81 (2), 851-883.

Nielsen, Thea, Alwin Keil, and Manfred Zeller, "Assessing Farmers' Risk Preferences and their Determinants in a Marginal Upland Area of Vietnam: A Comparison of Multiple Elicitation Techniques," Agricultural Economics, 2013, 44 (3), 255-273.

Ortoleva, Pietro, "Status Quo Bias, Multiple Priors and Uncertainty Aversion," Games and Economic Behavior, 2010, 69, 411-424.

Plott, Charles R. and K. Zeiler, "The Willingness to Pay-Willingness to Accept Gap, The 'Endowment Effect,' Subject Misconceptions, and Experimental Procedures for Eliciting Valuations," American Economic Review, 2005, 95 (3), 530-545.

Schmidt, Ulrich and Stefan T. Trautmann, "Common Consequence effects in Pricing and Choice," Theory and Decision, 2014, 76 (1), 1-7.

- and Stefan Traub, "An Experimental Investigation of the Disparity between WTA and WTP for Lotteries," Theory and Decision, 2009, 66 (3), 229-262.

Sokol-Hessner, Peter, Ming Hsu, Nina G. Curley, Mauricio R. Delgado, Colin F. Camerer, and Elizabeth A. Phelps, "Thinking like a Trader Selectively Reduces Individuals' Loss Aversion," Proceedings of the National Academy of Sciences, 2009, 106 (13), 5035-5040.

Sprenger, Charles, "An Endowment Effect for Risk: Experimental Tests of Stochastic Reference Points," Journal of Political Economy, 2015, 123 (6), 1456-1499.

Tunçel, Tuba and James K. Hammitt, "A New Meta-Analysis on the WTP/WTA Disparity," Journal of Environmental Economics and Management, 2014, 68 (1), 175-187.

Tversky, Amos, "Intransitivity of Preferences," Psychological Review, 1969, 76 (1), 31-48. 
- and Daniel Kahneman, "Loss Aversion in Riskless Choice: A Reference-Dependent Model," Quarterly Journal of Economics, 1991, 106 (4), 1039-1061.

Weber, Bernd, Andreas Aholt, Carolin Neuhaus, Peter Trautner, Christian E. Elger, and Thorsten Teichert, "Neural Evidence for Reference-dependence in Realmarket-transactions," Neuroimage, 2007, 35 (1), 441-447.

Weber, Elke U. and Eric J. Johnson, "Decisions under Uncertainty: Psychological, Economic, and Neuroeconomic Explanations of Risk Preference," in Paul W. Glimcher, Ernst Fehr, Colin Camerer, and Russell Alan Poldrack, eds., Neuroeconomics: Decision Making and the Brain, New York, NY: Elsevier, 2008, pp. 127-144. 


\section{Online Appendix - Not Intended for Publication}

\section{A Unweighted Specifications}

Table A.1: Table 2, unweighted.

\begin{tabular}{ccccccc}
\hline \hline & \multicolumn{3}{c}{ Correlation between WTA and WTP } & \multicolumn{2}{c}{$\begin{array}{c}\text { Correlation within } \\
\text { Type }\end{array}$} \\
& Lottery 1 & Lottery 2 & Averages & ORIV & WTA & WTP \\
\hline Study 1, & $-0.05^{* *}$ & $-0.05^{*}$ & $-0.07^{* *}$ & $-0.08^{* *}$ & $0.69^{* * *}$ & $0.74^{* * *}$ \\
Wave 1 & $(.027)$ & $(.025)$ & $(.027)$ & $(.032)$ & $(.019)$ & $(.018)$ \\
\hline Study 1, & -0.02 & 0.02 & 0.01 & 0.01 & $0.66^{* * *}$ & $0.75^{* * *}$ \\
Wave 2 & $(.032)$ & $(.031)$ & $(.033)$ & $(.040)$ & $(.024)$ & $(.020)$ \\
\hline Study 2 & $-0.08^{* *}$ & -0.04 & $-0.07^{* *}$ & $-0.09^{* *}$ & $0.70^{* * *}$ & $0.78^{* * *}$ \\
& $(.035)$ & $(.036)$ & $(.036)$ & $(.044)$ & $(.030)$ & $(.025)$ \\
\hline \hline
\end{tabular}

Notes: ${ }^{* * *},{ }^{* *},{ }^{*}$ denote statistical significance at the $1 \%, 5 \%$, and $10 \%$ level, with bootstrapped standard errors from 10,000 simulations in parentheses. 


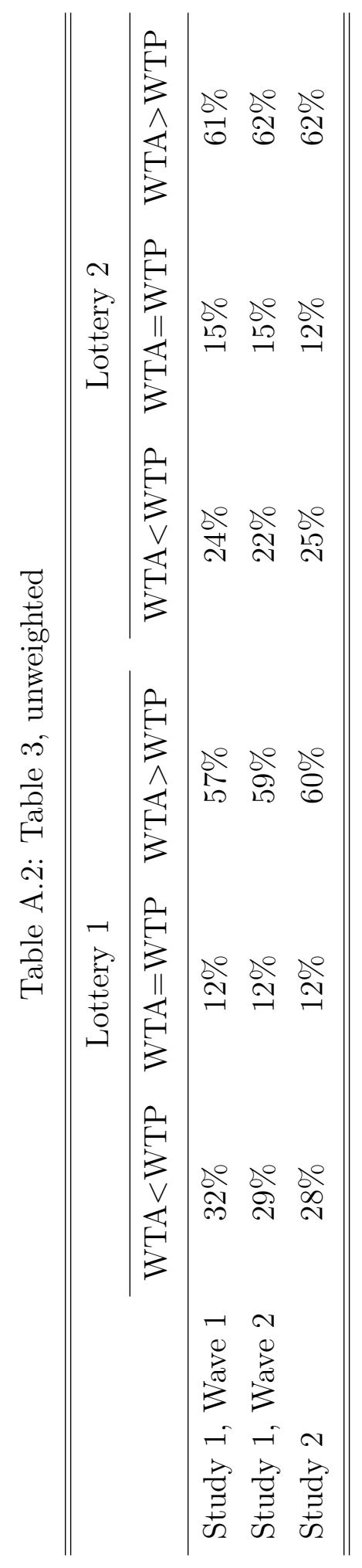

Online Appendix-2 
Figure A.1: Figure 1, unweighted.



Online Appendix-3 
Table A.3: Table 4, unweighted.

\begin{tabular}{|c|c|c|c|c|c|}
\hline & $\mathrm{N}$ & Lottery 1 & Lottery 2 & Average & ORIV \\
\hline All & 3,000 & $\begin{array}{c}-0.06^{* * *} \\
(.021)\end{array}$ & $\begin{array}{c}-0.05^{* *} \\
(.021)\end{array}$ & $\begin{array}{c}-0.06^{* * *} \\
(.021)\end{array}$ & $\begin{array}{c}-0.08^{* * *} \\
(.026)\end{array}$ \\
\hline Not Too Fast & 2,700 & $\begin{array}{l}-0.03 \\
(.022)\end{array}$ & $\begin{array}{l}-0.03 \\
(.022)\end{array}$ & $\begin{array}{c}-0.04^{*} \\
(.022)\end{array}$ & $\begin{array}{c}-0.05^{*} \\
(.027)\end{array}$ \\
\hline No Dominated Choices & 2,672 & $\begin{array}{c}-0.05^{* *} \\
(.024)\end{array}$ & $\begin{array}{c}-0.05^{* *} \\
(.022)\end{array}$ & $\begin{array}{c}-0.07^{* * *} \\
(.023)\end{array}$ & $\begin{array}{c}-0.08^{* * *} \\
(.027)\end{array}$ \\
\hline No Switches in Top or Bottom Two Rows & 1,595 & $\begin{array}{c}-0.08^{* * *} \\
(.031)\end{array}$ & $\begin{array}{c}-0.08^{* * *} \\
(.033)\end{array}$ & $\begin{array}{c}-0.08^{* * *} \\
(.032)\end{array}$ & $\begin{array}{c}-0.12^{* * *} \\
(.040)\end{array}$ \\
\hline No Switches in Top or Bottom Three Rows & 1,028 & $\begin{array}{l}-0.01 \\
(.036)\end{array}$ & $\begin{array}{c}0.02 \\
(.036)\end{array}$ & $\begin{array}{c}0.01 \\
(.037)\end{array}$ & $\begin{array}{l}-0.01 \\
(.054)\end{array}$ \\
\hline Question Order: WTA First & 1,501 & $\begin{array}{c}-0.07^{* *} \\
(.030)\end{array}$ & $\begin{array}{l}-0.04 \\
(.031)\end{array}$ & $\begin{array}{c}-0.06^{* *} \\
(.030)\end{array}$ & $\begin{array}{c}-0.08^{* *} \\
(.037)\end{array}$ \\
\hline Question Order: WTP First & 1,499 & $\begin{array}{c}-0.06^{*} \\
(.030)\end{array}$ & $\begin{array}{c}-0.06^{*} \\
(.029)\end{array}$ & $\begin{array}{c}-0.07^{* *} \\
(.031)\end{array}$ & $\begin{array}{c}-0.09^{* *} \\
(.037)\end{array}$ \\
\hline Education: HS or Less & 1,128 & $\begin{array}{c}-0.11^{* * *} \\
(.033)\end{array}$ & $\begin{array}{c}-0.06^{*} \\
(.034)\end{array}$ & $\begin{array}{c}-0.11^{* * *} \\
(.034)\end{array}$ & $\begin{array}{c}-0.13^{* * *} \\
(.041)\end{array}$ \\
\hline Education: Some College & 1,538 & $\begin{array}{l}-0.03 \\
(.031)\end{array}$ & $\begin{array}{l}-0.03 \\
(.030)\end{array}$ & $\begin{array}{l}-0.03 \\
(.031)\end{array}$ & $\begin{array}{l}-0.04 \\
(.037)\end{array}$ \\
\hline Education: Advanced Degree & 334 & $\begin{array}{c}0.00 \\
(.068)\end{array}$ & $\begin{array}{l}-0.04 \\
(.060)\end{array}$ & $\begin{array}{l}-0.02 \\
(.066)\end{array}$ & $\begin{array}{l}-0.05 \\
(.080)\end{array}$ \\
\hline Income: Above Median & 1,520 & $\begin{array}{c}0.00 \\
(.031)\end{array}$ & $\begin{array}{l}-0.03 \\
(.030)\end{array}$ & $\begin{array}{l}-0.01 \\
(.031)\end{array}$ & $\begin{array}{l}-0.02 \\
(.037)\end{array}$ \\
\hline Income: Top Quartile & 813 & $\begin{array}{c}0.04 \\
(.042)\end{array}$ & $\begin{array}{c}0.02 \\
(.041)\end{array}$ & $\begin{array}{c}0.05 \\
(.042)\end{array}$ & $\begin{array}{c}0.05 \\
(.053)\end{array}$ \\
\hline Income: Top Decile & 399 & $\begin{array}{c}0.09 \\
(.062)\end{array}$ & $\begin{array}{c}0.04 \\
(.059)\end{array}$ & $\begin{array}{c}0.07 \\
(.063)\end{array}$ & $\begin{array}{c}0.08 \\
(.078)\end{array}$ \\
\hline CRT: Above Median & 1,371 & $\begin{array}{l}0.08^{* *} \\
(.033)\end{array}$ & $\begin{array}{l}0.06^{*} \\
(.033)\end{array}$ & $\begin{array}{l}0.07^{* *} \\
(.034)\end{array}$ & $\begin{array}{l}0.09^{* *} \\
(.041)\end{array}$ \\
\hline CRT: Top Decile & 288 & $\begin{array}{c}0.10 \\
(.078)\end{array}$ & $\begin{array}{c}0.11 \\
(.076)\end{array}$ & $\begin{array}{c}0.10 \\
(.079)\end{array}$ & $\begin{array}{c}0.11 \\
(.093)\end{array}$ \\
\hline IQ: Above Median & 1,694 & $\begin{array}{l}-0.01 \\
(.029)\end{array}$ & $\begin{array}{l}-0.02 \\
(.027)\end{array}$ & $\begin{array}{l}-0.01 \\
(.029)\end{array}$ & $\begin{array}{l}-0.02 \\
(.034)\end{array}$ \\
\hline IQ: Top Decile & 337 & $\begin{array}{l}0.12^{*} \\
(.062)\end{array}$ & $\begin{array}{l}0.10^{*} \\
(.060)\end{array}$ & $\begin{array}{l}0.12^{* *} \\
(.061)\end{array}$ & $\begin{array}{l}0.14^{*} \\
(.075)\end{array}$ \\
\hline IQ: Top $5 \%$ & 146 & $\begin{array}{c}0.25^{* * *} \\
(.088)\end{array}$ & $\begin{array}{l}0.15^{*} \\
(.088)\end{array}$ & $\begin{array}{l}0.21^{* *} \\
(.085)\end{array}$ & $\begin{array}{c}0.26^{* *} \\
(.11)\end{array}$ \\
\hline Age: Youngest Quartile & 784 & $\begin{array}{l}-0.06 \\
(.043)\end{array}$ & $\begin{array}{c}-0.08^{* *} \\
(.041)\end{array}$ & $\begin{array}{c}-0.09^{* *} \\
(.043)\end{array}$ & $\begin{array}{c}-0.11^{* *} \\
(.052)\end{array}$ \\
\hline Age: Second Youngest Quartile & 730 & $\begin{array}{c}-0.08^{*} \\
(.043)\end{array}$ & $\begin{array}{l}-0.01 \\
(.046)\end{array}$ & $\begin{array}{l}-0.06 \\
(.044)\end{array}$ & $\begin{array}{l}-0.07 \\
(.052)\end{array}$ \\
\hline Age: Second Oldest Quartile & 786 & $\begin{array}{l}-0.06 \\
(.043)\end{array}$ & $\begin{array}{c}0.00 \\
(.040)\end{array}$ & $\begin{array}{l}-0.04 \\
(.041)\end{array}$ & $\begin{array}{l}-0.05 \\
(.050)\end{array}$ \\
\hline Age: Oldest Quartile & 700 & $\begin{array}{l}-0.05 \\
(.042)\end{array}$ & $\begin{array}{c}-0.10^{* *} \\
(.042)\end{array}$ & $\begin{array}{c}-0.07^{*} \\
(.043)\end{array}$ & $\begin{array}{c}-0.10^{*} \\
(.052)\end{array}$ \\
\hline
\end{tabular}

Notes: $^{* * *},{ }^{* *},{ }^{*}$ denote statistical significance at the $1 \%, 5 \%$, and $10 \%$ level, with bootstrapped standard errors from 10,000 simulations in parentheses.

Online Appendix-4 




Online Appendix-5 
Figure A.2: Figure 2, unweighted.


WTP (Averaged across two lotteries) 
Table A.5: Table 8, unweighted.

\begin{tabular}{|c|c|c|c|}
\hline $\begin{array}{l}\text { Dependent } \\
\text { Variable: }\end{array}$ & WTA & WTP & $\begin{array}{l}\text { Endowment } \\
\text { Effect }\end{array}$ \\
\hline \multicolumn{4}{|c|}{$\begin{array}{l}\text { Panel A: Theoretical Relationships with Loss Aversion } \\
\text { (Controlling for negative relationship with Risk Aversion) }\end{array}$} \\
\hline $\begin{array}{l}\text { Prospect Theory } \\
\text { (Standard) }\end{array}$ & + & 0 & + \\
\hline $\begin{array}{l}\text { Prospect Theory } \\
\text { (Alternative) }\end{array}$ & + & - & + \\
\hline $\begin{array}{l}\text { Stochastic Reference } \\
\text { Dependence }\end{array}$ & 0 & - & + \\
\hline \multicolumn{4}{|c|}{ Panel B: Study 1, Wave 1} \\
\hline Loss Aversion & $\begin{array}{c}-0.04^{*} \\
(.021)\end{array}$ & $\begin{array}{c}-0.07^{* * *} \\
(.021)\end{array}$ & $\begin{array}{c}0.02 \\
(.021)\end{array}$ \\
\hline Risk Aversion & $\begin{array}{l}-0.66^{* * *} \\
(.059)\end{array}$ & $\begin{array}{l}-0.52^{* * *} \\
(.061)\end{array}$ & $\begin{array}{c}-0.13^{* *} \\
(.062)\end{array}$ \\
\hline \multicolumn{4}{|c|}{ Panel C: Study 2 (IV Specification) } \\
\hline $\begin{array}{l}\text { Loss Aversion } \\
\text { (Mixed) }\end{array}$ & $\begin{array}{c}-0.28^{* * *} \\
(.051)\end{array}$ & $\begin{array}{c}0.06 \\
(.050)\end{array}$ & $\begin{array}{c}-0.25^{* * *} \\
(.049)\end{array}$ \\
\hline $\begin{array}{l}\text { Risk Aversion } \\
\text { (Gains) }\end{array}$ & $\begin{array}{c}-0.48^{* * *} \\
(.042)\end{array}$ & $\begin{array}{c}-0.12^{* * *} \\
(.039)\end{array}$ & $\begin{array}{c}-0.27^{* * *} \\
(.039)\end{array}$ \\
\hline $\begin{array}{l}\text { Risk Aversion } \\
\text { (Losses) }\end{array}$ & $\begin{array}{c}0.07 \\
(.051)\end{array}$ & $\begin{array}{c}0.38^{* * *} \\
(.062)\end{array}$ & $\begin{array}{c}-0.19^{* * *} \\
(.053)\end{array}$ \\
\hline
\end{tabular}

Notes: ${ }^{* *},{ }^{* *},{ }^{*}$ denote statistical significance at the $1 \%, 5 \%$, and $10 \%$ level. Standard errors in parentheses. Panel C displays bootstrapped standard errors from 10,000 simulations. 


\section{B Results for each Study / Wave}

Figure B.1: Figure 1 for Study 1, Wave 1 only.

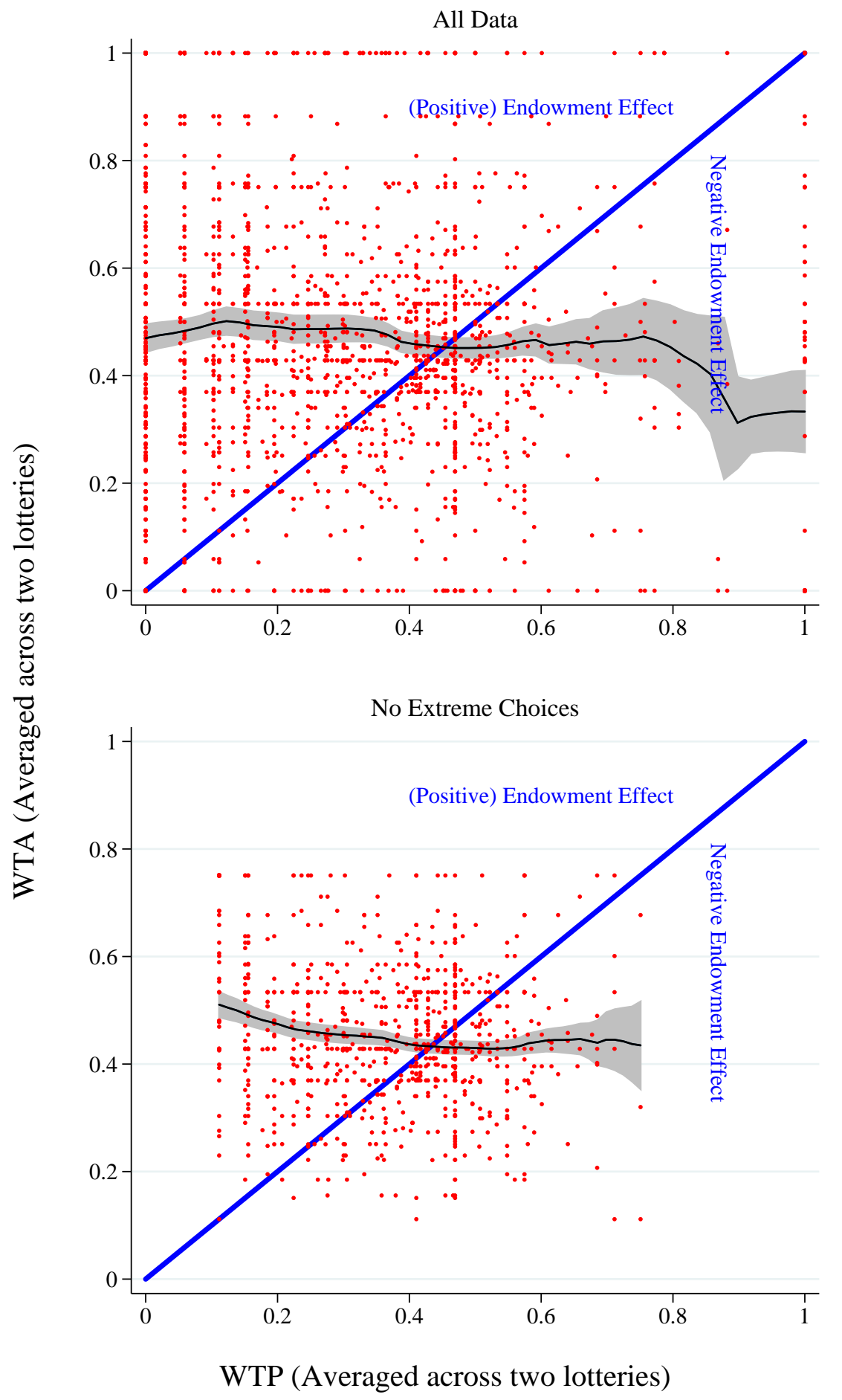

Online Appendix-8 
Table B.1: Table 4 for Study 1, Wave 1 only.

\begin{tabular}{|c|c|c|c|c|c|}
\hline & $\mathrm{N}$ & Lottery 1 & Lottery 2 & Average & ORIV \\
\hline All & 2,000 & $\begin{array}{l}-0.06^{*} \\
(.037)\end{array}$ & $\begin{array}{c}-0.06^{*} \\
(.037)\end{array}$ & $\begin{array}{c}-0.08^{* *} \\
(.037)\end{array}$ & $\begin{array}{c}-0.09^{* *} \\
(.044)\end{array}$ \\
\hline Not Too Fast & 1,800 & $\begin{array}{l}-0.03 \\
(.040)\end{array}$ & $\begin{array}{l}-0.04 \\
(.039)\end{array}$ & $\begin{array}{l}-0.05 \\
(.039)\end{array}$ & $\begin{array}{l}-0.06 \\
(.048)\end{array}$ \\
\hline No Dominated Choices & 2,000 & $\begin{array}{c}-0.06^{*} \\
(.037)\end{array}$ & $\begin{array}{c}-0.06^{*} \\
(.037)\end{array}$ & $\begin{array}{c}-0.08^{* *} \\
(.037)\end{array}$ & $\begin{array}{c}-0.09^{* *} \\
(.043)\end{array}$ \\
\hline No Switches in Top or Bottom Two Rows & 923 & $\begin{array}{c}-0.11^{*} \\
(.061)\end{array}$ & $\begin{array}{c}-0.14^{* * *} \\
(.051)\end{array}$ & $\begin{array}{c}-0.17^{* * *} \\
(.052)\end{array}$ & $\begin{array}{r}-0.23^{* * *} \\
(.071)\end{array}$ \\
\hline No Switches in Top or Bottom Three Rows & 629 & $\begin{array}{l}-0.06 \\
(.063)\end{array}$ & $\begin{array}{c}0.00 \\
(.069)\end{array}$ & $\begin{array}{l}-0.07 \\
(.077)\end{array}$ & $\begin{array}{c}-0.12 \\
(.12)\end{array}$ \\
\hline Question Order: WTA First & 1,011 & $\begin{array}{l}-0.06 \\
(.046)\end{array}$ & $\begin{array}{l}-0.07 \\
(.043)\end{array}$ & $\begin{array}{c}-0.08^{*} \\
(.044)\end{array}$ & $\begin{array}{c}-0.09^{*} \\
(.053)\end{array}$ \\
\hline Question Order: WTP First & 989 & $\begin{array}{l}-0.06 \\
(.057)\end{array}$ & $\begin{array}{l}-0.06 \\
(.058)\end{array}$ & $\begin{array}{l}-0.08 \\
(.058)\end{array}$ & $\begin{array}{l}-0.09 \\
(.068)\end{array}$ \\
\hline Education: HS or Less & 765 & $\begin{array}{c}-0.13^{* *} \\
(.059)\end{array}$ & $\begin{array}{l}-0.09 \\
(.064)\end{array}$ & $\begin{array}{c}-0.13^{* *} \\
(.061)\end{array}$ & $\begin{array}{c}-0.16^{* *} \\
(.071)\end{array}$ \\
\hline Education: Some College & 1,018 & $\begin{array}{l}-0.01 \\
(.050)\end{array}$ & $\begin{array}{l}-0.04 \\
(.044)\end{array}$ & $\begin{array}{l}-0.03 \\
(.050)\end{array}$ & $\begin{array}{l}-0.04 \\
(.057)\end{array}$ \\
\hline Education: Advanced Degree & 217 & $\begin{array}{c}0.05 \\
(.093)\end{array}$ & $\begin{array}{l}-0.02 \\
(.079)\end{array}$ & $\begin{array}{c}0.00 \\
(.089)\end{array}$ & $\begin{array}{l}0.01 \\
(.11)\end{array}$ \\
\hline Income: Above Median & 1,004 & $\begin{array}{l}-0.04 \\
(.046)\end{array}$ & $\begin{array}{l}-0.03 \\
(.053)\end{array}$ & $\begin{array}{l}-0.04 \\
(.046)\end{array}$ & $\begin{array}{l}-0.05 \\
(.056)\end{array}$ \\
\hline Income: Top Quartile & 540 & $\begin{array}{l}-0.03 \\
(.069)\end{array}$ & $\begin{array}{c}0.04 \\
(.077)\end{array}$ & $\begin{array}{c}0.01 \\
(.069)\end{array}$ & $\begin{array}{c}0.01 \\
(.084)\end{array}$ \\
\hline Income: Top Decile & 275 & $\begin{array}{c}0.12 \\
(.085)\end{array}$ & $\begin{array}{c}0.00 \\
(.080)\end{array}$ & $\begin{array}{c}0.06 \\
(.088)\end{array}$ & $\begin{array}{l}0.08 \\
(.11)\end{array}$ \\
\hline CRT: Above Median & 913 & $\begin{array}{l}0.12^{* *} \\
(.053)\end{array}$ & $\begin{array}{c}0.04 \\
(.049)\end{array}$ & $\begin{array}{c}0.08 \\
(.052)\end{array}$ & $\begin{array}{c}0.10 \\
(.065)\end{array}$ \\
\hline CRT: Top Decile & 189 & $\begin{array}{c}0.16 \\
(.100)\end{array}$ & $\begin{array}{l}0.21^{* *} \\
(.097)\end{array}$ & $\begin{array}{l}0.16 \\
(.10)\end{array}$ & $\begin{array}{l}0.19 \\
(.13)\end{array}$ \\
\hline IQ: Above Median & 1,117 & $\begin{array}{l}-0.01 \\
(.049)\end{array}$ & $\begin{array}{l}-0.05 \\
(.043)\end{array}$ & $\begin{array}{l}-0.04 \\
(.047)\end{array}$ & $\begin{array}{l}-0.05 \\
(.057)\end{array}$ \\
\hline IQ: Top Decile & 232 & $\begin{array}{c}0.10 \\
(.112)\end{array}$ & $\begin{array}{c}0.09 \\
(.095)\end{array}$ & $\begin{array}{l}0.09 \\
(.11)\end{array}$ & $\begin{array}{l}0.11 \\
(.14)\end{array}$ \\
\hline IQ: Top 5\% & 97 & $\begin{array}{c}0.30^{* * *} \\
(.113)\end{array}$ & $\begin{array}{c}0.16 \\
(.127)\end{array}$ & $\begin{array}{l}0.20^{*} \\
(.12)\end{array}$ & $\begin{array}{l}0.29 \\
(.22)\end{array}$ \\
\hline Age: Youngest Quartile & 374 & $\begin{array}{c}-0.17^{*} \\
(.093)\end{array}$ & $\begin{array}{c}-0.19^{* *} \\
(.087)\end{array}$ & $\begin{array}{c}-0.23^{* *} \\
(.094)\end{array}$ & $\begin{array}{c}-0.27^{* *} \\
(.11)\end{array}$ \\
\hline Age: Second Youngest Quartile & 563 & $\begin{array}{c}0.01 \\
(.070)\end{array}$ & $\begin{array}{c}0.00 \\
(.069)\end{array}$ & $\begin{array}{c}0.00 \\
(.064)\end{array}$ & $\begin{array}{c}0.00 \\
(.077)\end{array}$ \\
\hline Age: Second Oldest Quartile & 582 & $\begin{array}{l}-0.08 \\
(.059)\end{array}$ & $\begin{array}{l}-0.07 \\
(.052)\end{array}$ & $\begin{array}{l}-0.09 \\
(.058)\end{array}$ & $\begin{array}{l}-0.11 \\
(.068)\end{array}$ \\
\hline Age: Oldest Quartile & 481 & $\begin{array}{c}0.00 \\
(.060)\end{array}$ & $\begin{array}{c}0.00 \\
(.071)\end{array}$ & $\begin{array}{c}0.01 \\
(.058)\end{array}$ & $\begin{array}{c}0.01 \\
(.072)\end{array}$ \\
\hline
\end{tabular}

Notes: ${ }^{* * *},{ }^{* *},{ }^{*}$ denote statistical significance at the $1 \%, 5 \%$, and $10 \%$ level, with bootstrapped standard errors from 10,000 simulations in parentheses. 
Figure B.2: Figure 2 for Study 1, Wave 1 only.


CRT: Above Median
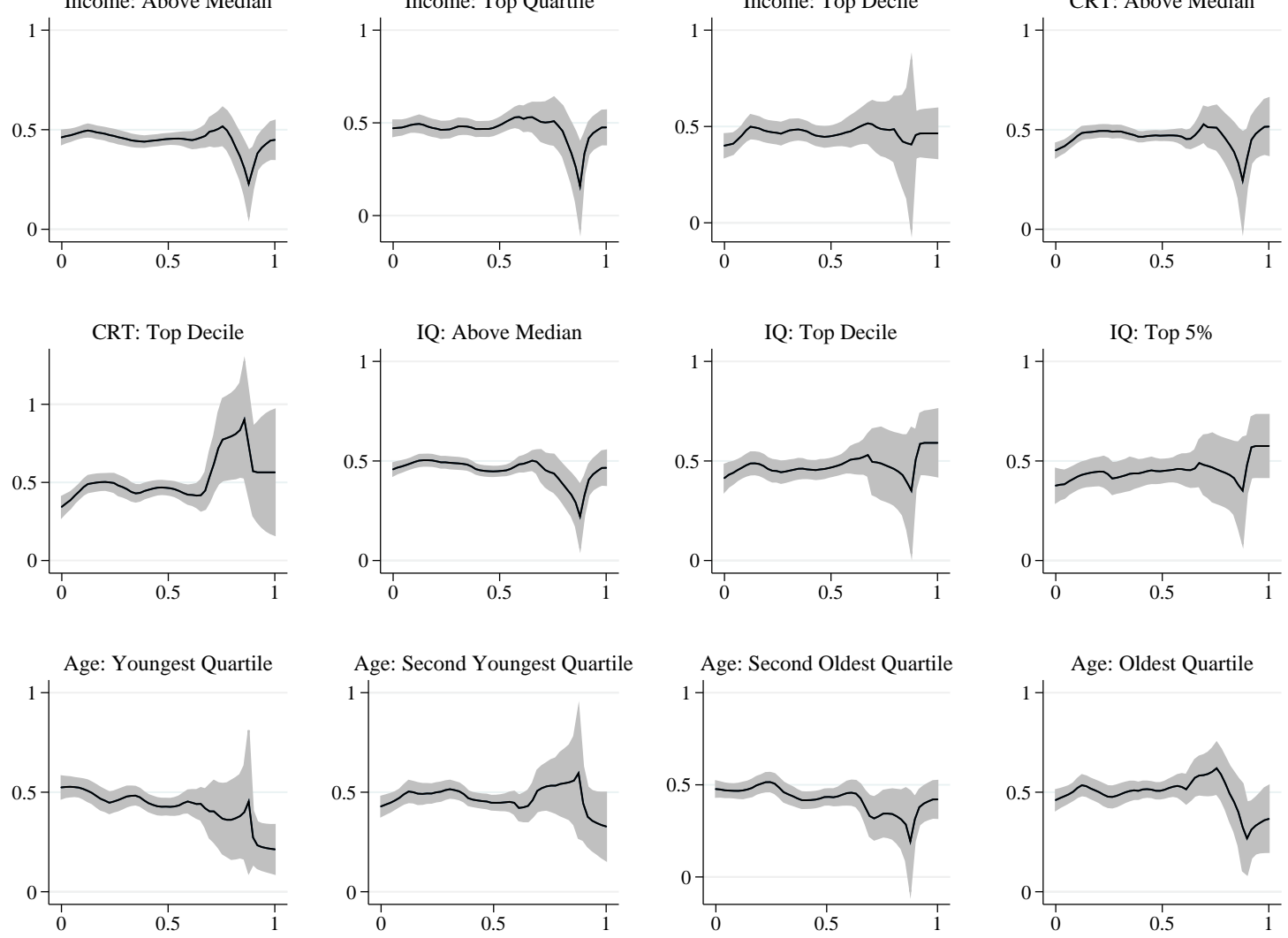

WTP (Averaged across two lotteries) 
Figure B.3: Figure 1 for Study 1, Wave 2 only.



Online Appendix-11 
Table B.2: Table 4 for Study 1, Wave 2 only.

\begin{tabular}{|c|c|c|c|c|c|}
\hline & $\mathrm{N}$ & Lottery 1 & Lottery 2 & Average & ORIV \\
\hline All & 1,465 & $\begin{array}{l}-0.01 \\
(.050)\end{array}$ & $\begin{array}{l}-0.02 \\
(.049)\end{array}$ & $\begin{array}{l}-0.02 \\
(.053)\end{array}$ & $\begin{array}{l}-0.02 \\
(.063)\end{array}$ \\
\hline Not Too Fast & 1,319 & $\begin{array}{c}0.00 \\
(.052)\end{array}$ & $\begin{array}{l}-0.02 \\
(.052)\end{array}$ & $\begin{array}{l}-0.01 \\
(.057)\end{array}$ & $\begin{array}{c}-0.01 \\
(.069)\end{array}$ \\
\hline No Dominated Choices & 1,465 & $\begin{array}{l}-0.01 \\
(.050)\end{array}$ & $\begin{array}{l}-0.02 \\
(.049)\end{array}$ & $\begin{array}{l}-0.02 \\
(.053)\end{array}$ & $\begin{array}{l}-0.02 \\
(.063)\end{array}$ \\
\hline No Switches in Top or Bottom Two Rows & 717 & $\begin{array}{c}0.05 \\
(.058)\end{array}$ & $\begin{array}{c}-0.13^{* * *} \\
(.051)\end{array}$ & $\begin{array}{l}-0.05 \\
(.052)\end{array}$ & $\begin{array}{l}-0.06 \\
(.073)\end{array}$ \\
\hline No Switches in Top or Bottom Three Rows & 483 & $\begin{array}{c}0.10 \\
(.080)\end{array}$ & $\begin{array}{l}-0.04 \\
(.061)\end{array}$ & $\begin{array}{c}0.02 \\
(.070)\end{array}$ & $\begin{array}{l}0.04 \\
(.11)\end{array}$ \\
\hline Question Order: WTA First & 754 & $\begin{array}{c}0.00 \\
(.069)\end{array}$ & $\begin{array}{c}0.07 \\
(.069)\end{array}$ & $\begin{array}{l}0.04 \\
(.075)\end{array}$ & $\begin{array}{c}0.05 \\
(.088)\end{array}$ \\
\hline Question Order: WTP First & 711 & $\begin{array}{l}-0.03 \\
(.071)\end{array}$ & $\begin{array}{l}-0.12^{*} \\
(.064)\end{array}$ & $\begin{array}{l}-0.08 \\
(.074)\end{array}$ & $\begin{array}{l}-0.09 \\
(.088)\end{array}$ \\
\hline Education: HS or Less & 525 & $\begin{array}{l}-0.02 \\
(.071)\end{array}$ & $\begin{array}{l}-0.06 \\
(.075)\end{array}$ & $\begin{array}{l}-0.05 \\
(.077)\end{array}$ & $\begin{array}{l}-0.05 \\
(.088)\end{array}$ \\
\hline Education: Some College & 774 & $\begin{array}{c}0.00 \\
(.075)\end{array}$ & $\begin{array}{l}-0.01 \\
(.072)\end{array}$ & $\begin{array}{c}0.00 \\
(.083)\end{array}$ & $\begin{array}{l}0.00 \\
(.10)\end{array}$ \\
\hline Education: Advanced Degree & 166 & $\begin{array}{l}-0.06 \\
(.089)\end{array}$ & $\begin{array}{c}0.08 \\
(.090)\end{array}$ & $\begin{array}{c}0.04 \\
(.087)\end{array}$ & $\begin{array}{l}0.04 \\
(.11)\end{array}$ \\
\hline Income: Above Median & 751 & $\begin{array}{c}0.06 \\
(.064)\end{array}$ & $\begin{array}{l}0.13^{* *} \\
(.061)\end{array}$ & $\begin{array}{l}0.11^{*} \\
(.064)\end{array}$ & $\begin{array}{l}0.13^{*} \\
(.076)\end{array}$ \\
\hline Income: Top Quartile & 389 & $\begin{array}{c}0.05 \\
(.087)\end{array}$ & $\begin{array}{l}0.12^{*} \\
(.073)\end{array}$ & $\begin{array}{c}0.11 \\
(.076)\end{array}$ & $\begin{array}{c}0.14 \\
(.094)\end{array}$ \\
\hline Income: Top Decile & 203 & $\begin{array}{c}0.02 \\
(.126)\end{array}$ & $\begin{array}{c}0.12 \\
(.106)\end{array}$ & $\begin{array}{c}0.07 \\
(.113)\end{array}$ & $\begin{array}{c}0.08 \\
(.138)\end{array}$ \\
\hline CRT: Above Median & 702 & $\begin{array}{l}0.12^{* *} \\
(.058)\end{array}$ & $\begin{array}{l}0.12^{* *} \\
(.053)\end{array}$ & $\begin{array}{c}0.15^{* * *} \\
(.054)\end{array}$ & $\begin{array}{c}0.19^{* * *} \\
(.068)\end{array}$ \\
\hline CRT: Top Decile & 190 & $\begin{array}{l}0.18^{*} \\
(.11)\end{array}$ & $\begin{array}{l}0.04 \\
(.12)\end{array}$ & $\begin{array}{l}0.13 \\
(.11)\end{array}$ & $\begin{array}{l}0.18 \\
(.16)\end{array}$ \\
\hline IQ: Above Median & 855 & $\begin{array}{l}-0.01 \\
(.067)\end{array}$ & $\begin{array}{c}0.02 \\
(.064)\end{array}$ & $\begin{array}{c}0.01 \\
(.072)\end{array}$ & $\begin{array}{c}0.02 \\
(.090)\end{array}$ \\
\hline IQ: Top Decile & 208 & $\begin{array}{l}0.20^{* *} \\
(.098)\end{array}$ & $\begin{array}{c}0.29^{* *} \\
(.13)\end{array}$ & $\begin{array}{c}0.30^{* *} \\
(.12)\end{array}$ & $\begin{array}{c}0.36^{* *} \\
(.14)\end{array}$ \\
\hline IQ: Top $5 \%$ & 95 & $\begin{array}{l}0.30^{* *} \\
(.142)\end{array}$ & $\begin{array}{l}0.23^{* *} \\
(.114)\end{array}$ & $\begin{array}{c}0.29^{* *} \\
(.13)\end{array}$ & $\begin{array}{c}0.35^{* *} \\
(.17)\end{array}$ \\
\hline Age: Youngest Quartile & 252 & $\begin{array}{c}-0.05 \\
(.12)\end{array}$ & $\begin{array}{c}-0.11 \\
(.11)\end{array}$ & $\begin{array}{c}-0.09 \\
(.13)\end{array}$ & $\begin{array}{c}-0.11 \\
(.16)\end{array}$ \\
\hline Age: Second Youngest Quartile & 389 & $\begin{array}{l}0.04 \\
(.11)\end{array}$ & $\begin{array}{l}0.06 \\
(.11)\end{array}$ & $\begin{array}{l}0.07 \\
(.12)\end{array}$ & $\begin{array}{l}0.08 \\
(.13)\end{array}$ \\
\hline Age: Second Oldest Quartile & 442 & $\begin{array}{l}-0.03 \\
(.083)\end{array}$ & $\begin{array}{l}-0.04 \\
(.076)\end{array}$ & $\begin{array}{l}-0.04 \\
(.084)\end{array}$ & $\begin{array}{c}-0.05 \\
(.10)\end{array}$ \\
\hline Age: Oldest Quartile & 382 & $\begin{array}{l}-0.02 \\
(.073)\end{array}$ & $\begin{array}{l}-0.01 \\
(.069)\end{array}$ & $\begin{array}{c}0.00 \\
(.071)\end{array}$ & $\begin{array}{c}0.00 \\
(.087)\end{array}$ \\
\hline
\end{tabular}

Notes: ${ }^{* * *},{ }^{* *},{ }^{*}$ denote statistical significance at the $1 \%, 5 \%$, and $10 \%$ level, with bootstrapped standard errors from 10,000 simulations in parentheses. 
Figure B.4: Figure 2 for Study 1, Wave 2 only.


CRT: Above Median
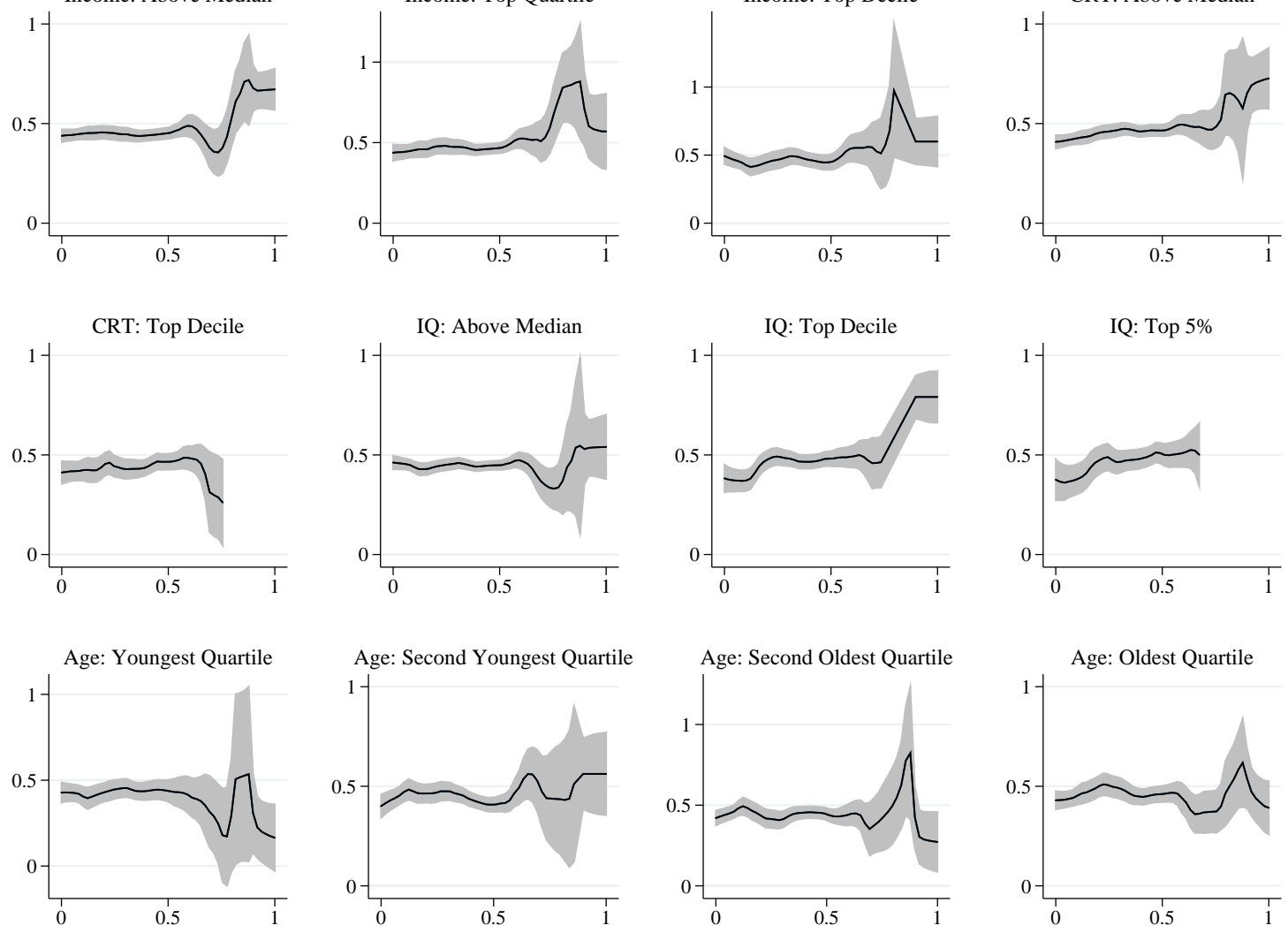

WTP (Averaged across two lotteries) 
Figure B.5: Figure 1 for Study 2 only.

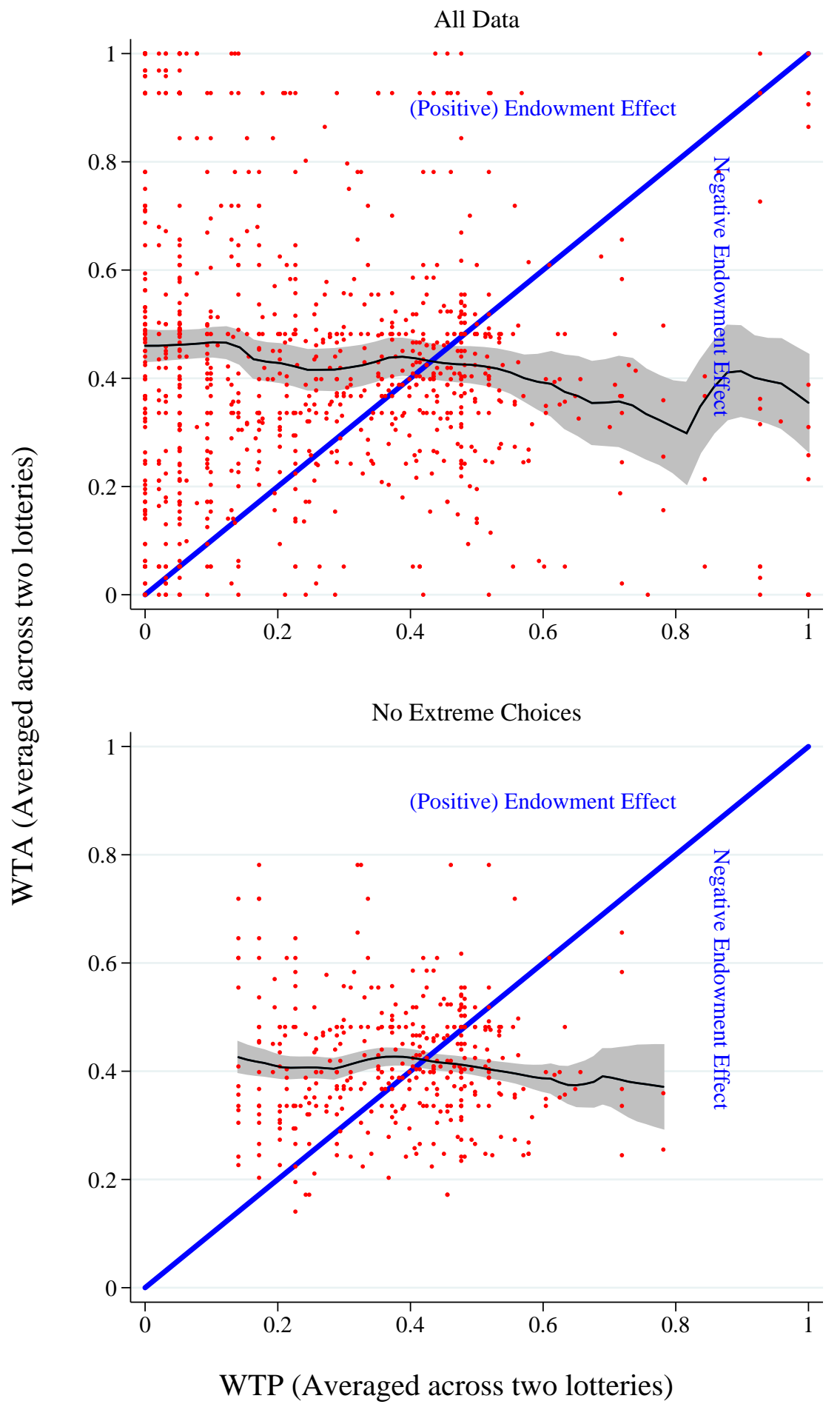

Online Appendix-14 
Table B.3: Table 4 for Study 2 only.

\begin{tabular}{|c|c|c|c|c|c|}
\hline & $\mathrm{N}$ & Lottery 1 & Lottery 2 & Average & ORIV \\
\hline All & 1,000 & $\begin{array}{c}-0.09^{*} \\
(.051)\end{array}$ & $\begin{array}{l}-0.06 \\
(.055)\end{array}$ & $\begin{array}{l}-0.09 \\
(.057)\end{array}$ & $\begin{array}{l}-0.11 \\
(.068)\end{array}$ \\
\hline Not Too Fast & 900 & $\begin{array}{c}-0.12^{* * *} \\
(.045)\end{array}$ & $\begin{array}{c}-0.09^{*} \\
(.050)\end{array}$ & $\begin{array}{c}-0.13^{* * *} \\
(.049)\end{array}$ & $\begin{array}{c}-0.16^{* * *} \\
(.059)\end{array}$ \\
\hline No Dominated Choices & 672 & $\begin{array}{c}-0.10^{*} \\
(.057)\end{array}$ & $\begin{array}{c}-0.13^{* *} \\
(.059)\end{array}$ & $\begin{array}{c}-0.13^{* *} \\
(.057)\end{array}$ & $\begin{array}{c}-0.15^{* *} \\
(.067)\end{array}$ \\
\hline No Switches in Top or Bottom Two Rows & 672 & $\begin{array}{c}-0.10^{*} \\
(.058)\end{array}$ & $\begin{array}{c}-0.13^{* *} \\
(.059)\end{array}$ & $\begin{array}{c}-0.13^{* *} \\
(.057)\end{array}$ & $\begin{array}{c}-0.15^{* * *} \\
(.066)\end{array}$ \\
\hline No Switches in Top or Bottom Three Rows & 399 & $\begin{array}{l}-0.03 \\
(.098)\end{array}$ & $\begin{array}{l}-0.11 \\
(.071)\end{array}$ & $\begin{array}{l}-0.07 \\
(.075)\end{array}$ & $\begin{array}{c}-0.10 \\
(.11)\end{array}$ \\
\hline Question Order: WTA First & 490 & $\begin{array}{l}-0.06 \\
(.084)\end{array}$ & $\begin{array}{l}-0.04 \\
(.088)\end{array}$ & $\begin{array}{l}-0.06 \\
(.091)\end{array}$ & $\begin{array}{c}-0.06 \\
(.10)\end{array}$ \\
\hline Question Order: WTP First & 510 & $\begin{array}{c}-0.13^{* *} \\
(.055)\end{array}$ & $\begin{array}{l}-0.09 \\
(.060)\end{array}$ & $\begin{array}{c}-0.13^{* *} \\
(.059)\end{array}$ & $\begin{array}{c}-0.17^{* *} \\
(.075)\end{array}$ \\
\hline Education: HS or Less & 363 & $\begin{array}{l}-0.08 \\
(.087)\end{array}$ & $\begin{array}{l}-0.00 \\
(.094)\end{array}$ & $\begin{array}{c}-0.06 \\
(.10)\end{array}$ & $\begin{array}{c}-0.07 \\
(.12)\end{array}$ \\
\hline Education: Some College & 520 & $\begin{array}{l}-0.09 \\
(.059)\end{array}$ & $\begin{array}{c}-0.10^{*} \\
(.062)\end{array}$ & $\begin{array}{c}-0.11^{*} \\
(.062)\end{array}$ & $\begin{array}{c}-0.13^{*} \\
(.072)\end{array}$ \\
\hline Education: Advanced Degree & 117 & $\begin{array}{c}-0.12 \\
(.12)\end{array}$ & $\begin{array}{c}-0.18^{*} \\
(.10)\end{array}$ & $\begin{array}{c}-0.15 \\
(.11)\end{array}$ & $\begin{array}{c}-0.18 \\
(.14)\end{array}$ \\
\hline Income: Above Median & 516 & $\begin{array}{l}-0.04 \\
(.062)\end{array}$ & $\begin{array}{c}-0.11^{*} \\
(.061)\end{array}$ & $\begin{array}{l}-0.07 \\
(.063)\end{array}$ & $\begin{array}{l}-0.08 \\
(.075)\end{array}$ \\
\hline Income: Top Quartile & 273 & $\begin{array}{c}0.02 \\
(.082)\end{array}$ & $\begin{array}{l}-0.08 \\
(.079)\end{array}$ & $\begin{array}{l}-0.01 \\
(.083)\end{array}$ & $\begin{array}{c}-0.02 \\
(.10)\end{array}$ \\
\hline Income: Top Decile & 124 & $\begin{array}{c}-0.08 \\
(.13)\end{array}$ & $\begin{array}{c}-0.07 \\
(.11)\end{array}$ & $\begin{array}{c}-0.08 \\
(.13)\end{array}$ & $\begin{array}{c}-0.10 \\
(.15)\end{array}$ \\
\hline CRT: Above Median & 458 & $\begin{array}{c}0.08 \\
(.068)\end{array}$ & $\begin{array}{c}0.07 \\
(.071)\end{array}$ & $\begin{array}{l}0.09 \\
(.071)\end{array}$ & $\begin{array}{c}0.11 \\
(.088)\end{array}$ \\
\hline CRT: Top Decile & 99 & $\begin{array}{c}-0.07 \\
(.13)\end{array}$ & $\begin{array}{c}-0.05 \\
(.14)\end{array}$ & $\begin{array}{c}-0.05 \\
(.14)\end{array}$ & $\begin{array}{c}-0.06 \\
(.16)\end{array}$ \\
\hline IQ: Above Median & 577 & $\begin{array}{l}-0.09 \\
(.057)\end{array}$ & $\begin{array}{l}-0.09 \\
(.059)\end{array}$ & $\begin{array}{c}-0.10^{*} \\
(.058)\end{array}$ & $\begin{array}{l}-0.11^{*} \\
(.065)\end{array}$ \\
\hline IQ: Top Decile & 105 & $\begin{array}{l}0.10 \\
(.12)\end{array}$ & $\begin{array}{l}0.05 \\
(.12)\end{array}$ & $\begin{array}{l}0.07 \\
(.12)\end{array}$ & $\begin{array}{l}0.08 \\
(.13)\end{array}$ \\
\hline IQ: Top 5\% & 49 & $\begin{array}{l}0.26^{*} \\
(.15)\end{array}$ & $\begin{array}{l}0.17 \\
(.15)\end{array}$ & $\begin{array}{l}0.23 \\
(.15)\end{array}$ & $\begin{array}{l}0.25 \\
(.17)\end{array}$ \\
\hline Age: Youngest Quartile & 218 & $\begin{array}{c}-0.27^{* * *} \\
(.082)\end{array}$ & $\begin{array}{c}-0.25^{* * *} \\
(.094)\end{array}$ & $\begin{array}{c}-0.30^{* * *} \\
(.089)\end{array}$ & $\begin{array}{c}-0.39^{* * *} \\
(.11)\end{array}$ \\
\hline Age: Second Youngest Quartile & 262 & $\begin{array}{c}-0.20^{* * *} \\
(.076)\end{array}$ & $\begin{array}{c}-0.19^{* *} \\
(.086)\end{array}$ & $\begin{array}{c}-0.21^{* *} \\
(.085)\end{array}$ & $\begin{array}{c}-0.25^{* *} \\
(.099)\end{array}$ \\
\hline Age: Second Oldest Quartile & 263 & $\begin{array}{l}0.14 \\
(.11)\end{array}$ & $\begin{array}{l}0.21^{*} \\
(.11)\end{array}$ & $\begin{array}{l}0.17 \\
(.12)\end{array}$ & $\begin{array}{l}0.19 \\
(.13)\end{array}$ \\
\hline Age: Oldest Quartile & 257 & $\begin{array}{l}-0.11 \\
(.087)\end{array}$ & $\begin{array}{l}-0.11 \\
(.083)\end{array}$ & $\begin{array}{l}-0.13 \\
(.088)\end{array}$ & $\begin{array}{c}-0.16 \\
(.11)\end{array}$ \\
\hline
\end{tabular}

Notes: ${ }^{* * *},{ }^{* *},{ }^{*}$ denote statistical significance at the $1 \%, 5 \%$, and $10 \%$ level, with bootstrapped standard errors from 10,000 simulations in parentheses.

Online Appendix-15 
Figure B.6: Figure 2 for Study 2 only.


WTP (Averaged across two lotteries) 


\section{Plott and Zeiler (2005) Training Rounds}

Table C.1: Data from Plott and Zeiler Training Rounds

\begin{tabular}{|c|c|c|c|c|}
\hline Study & $\begin{array}{l}\text { Group } \\
(\mathrm{N})\end{array}$ & Lottery & Correlation & WTA $<$ WTP \\
\hline \multirow{10}{*}{$\begin{array}{l}\text { Plott and } \\
\text { Zeiler (2005) }\end{array}$} & \multirow{5}{*}{$\begin{array}{c}1 \\
(38)\end{array}$} & $0.3 *-0.1 \oplus 0.7 * 0.8$ & $\begin{array}{l}0.15 \\
(.17)\end{array}$ & $20 \%$ \\
\hline & & $0.3 * 1 \oplus 0.7 * 11$ & $\begin{array}{l}0.26 \\
(.16)\end{array}$ & $20 \%$ \\
\hline & & $0.4 * 1 \oplus 0.6 * 6$ & $\begin{array}{c}0.53^{* * *} \\
(.14)\end{array}$ & $8 \%$ \\
\hline & & $0.5 *-3 \oplus 0.5 * 9$ & $\begin{array}{l}0.11 \\
(.17)\end{array}$ & $17 \%$ \\
\hline & & $0.7 * 1 \oplus 0.3 * 8$ & $\begin{array}{l}0.21 \\
(.16)\end{array}$ & $17 \%$ \\
\hline & \multirow{5}{*}{$\begin{array}{c}2 \\
(36)\end{array}$} & $0.3 * 1 \oplus 0.7 * 8$ & $\begin{array}{c}0.39^{* * *} \\
(.16)\end{array}$ & $29 \%$ \\
\hline & & $0.5 *-3 \oplus 0.5 * 9$ & $\begin{array}{c}0.61^{* * *} \\
(.14)\end{array}$ & $32 \%$ \\
\hline & & $0.6 * 1 \oplus 0.4 * 6$ & $\begin{array}{l}0.20 \\
(.17)\end{array}$ & $13 \%$ \\
\hline & & $0.7 *-0.1 \oplus 0.3 * 0.8$ & $\begin{array}{c}0.69^{* * *} \\
(.13)\end{array}$ & $21 \%$ \\
\hline & & $0.7 * 1 \oplus 0.3 * 11$ & $\begin{array}{c}0.55^{* * *} \\
(.14)\end{array}$ & $8 \%$ \\
\hline
\end{tabular}

Notes: ${ }^{* * *},{ }^{* *},{ }^{*}$ denote statistical significance at the $1 \%, 5 \%$, and $10 \%$ level. Correlations with standard errors in parentheses.

\section{Screenshots and Analysis of MPL Ordering}

Descriptions of the WTA and WTP questions, as drawn from our design documents, are shown in the text. Here, we display screenshots of the WTA and WTP questions from Study 2. Complete design documents are available at hss.caltech.edu/ snowberg/wep.html. We also explore the consequences of the different ordering of the MPLs, including varying 
the order experimentally.

Figure D.1: WTA, Lottery 1.

\section{YouGov}

For this question, you are given a lottery ticket that has a $\mathbf{5 0} \%$ chance of paying you $\mathbf{9 , 0 0 0}$ points, and a $\mathbf{5 0} \%$ chance of paying you 1,000 points.

You have two options for this lottery ticket:

1. Keep it or

2. Sell it for a certain amount of points (for example, 3,000 points)

For each row in the table below, which option would you prefer?

$\begin{array}{lll}\text { The lottery ticket } & \text { or } & \text { Sell it for } 0 \text { points } \\ \text { The lottery ticket } & \text { or } & \text { Sell it for } 1,000 \text { points } \\ \text { The lottery ticket } & \text { or } & \text { Sell it for } 2,000 \text { points } \\ \text { The lottery ticket } & \text { or } & \text { Sell it for } 2,500 \text { points } \\ \text { The lottery ticket } & \text { or } & \text { Sell it for } 3,000 \text { points } \\ \text { The lottery ticket } & \text { or } & \text { Sell it for } 3,250 \text { points } \\ \text { The lottery ticket } & \text { or } & \text { Sell it for } 3,500 \text { points } \\ \text { The lottery ticket } & \text { or } & \text { Sell it for } 3,750 \text { points } \\ \text { The lottery ticket } & \text { or } & \text { Sell it for } 4,000 \text { points } \\ \text { The lottery ticket } & \text { or } & \text { Sell it for } 4,250 \text { points } \\ \text { The lottery ticket } & \text { or } & \text { Sell it for } 4,500 \text { points } \\ \text { The lottery ticket } & \text { or } & \text { Sell it for } 4,750 \text { points } \\ \text { The lottery ticket } & \text { or } & \text { Sell it for } 5,000 \text { points } \\ \text { The lottery ticket } & \text { or } & \text { Sell it for } 5,250 \text { points } \\ \text { The lottery ticket } & \text { or } & \text { Sell it for } 5,500 \text { points } \\ \text { The lottery ticket } & \text { or } & \text { Sell it for } 6,000 \text { points } \\ \text { The lottery ticket } & \text { or } & \text { Sell it for } 7,000 \text { points } \\ \text { The lottery ticket } & \text { or } & \text { oell it for } 8,000 \text { points } \\ \text { The lottery ticket } & \text { or } & \text { oell it for } 9,000 \text { points } \\ \text { The lottery ticket } & \text { or } & \text { Sell it for } 10,000 \text { points }\end{array}$


Figure D.2: WTA, Lottery 2.

\section{YouGov}

For this question, you are given a lottery ticket that has a $\mathbf{5 0} \%$ chance of paying you $\mathbf{8 , 0 0 0}$ points, and a $\mathbf{5 0} \%$ chance of paying you 2,000 points.

You have two options for this lottery:

1. Keep it

2. Sell it for a certain amount of points (for example, 3,000 points)

For each row in the table below, which option would you prefer?

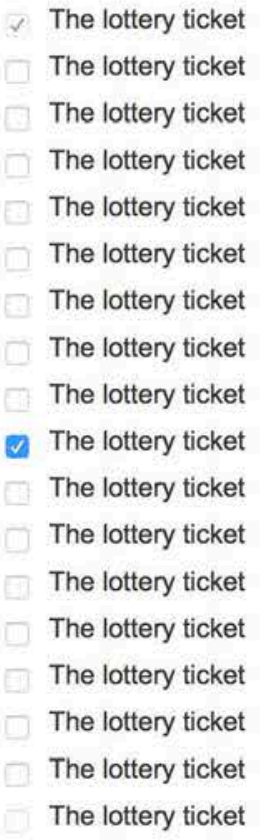

Sell it for 1,500 points

Sell it for 2,000 points

Sell it for 2,500 points

Sell it for 3,000 points

Sell it for 3,250 points

Sell it for 3,500 points

Sell it for 3,750 points

Sell it for 4,000 points

Sell it for 4,250 points

Sell it for 4,500 points

Sell it for 4,750 points

Sell it for 5,000 points

Sell it for 5,250 points

Sell it for 5,500 points

Sell it for 6,000 points

Sell it for 7,000 points

Sell it for 8,000 points

Sell it for 9,000 points

Review the instructions 


\section{Figure D.3: WTP, Lottery 1.}

\section{YouGov}

For this question, you have been given 10,000 points. You will be offered the opportunity to exchange some of these points for a lottery ticket. This lottery ticket has a $50 \%$ chance of paying you 9,000 points, and a $50 \%$ chance of paying 1,000 points.

For example, if you choose to pay 2,000 points for a lottery ticket, and this question is chosen for payment, you will:

- Pay 2,000 points for the lottery ticket

- Keep 8,000 points for yourself

- Earn whatever proceeds you get from the lottery ticket (if any)

For each row in the table below, which option would you prefer?

\begin{tabular}{|c|c|c|c|}
\hline Keep 10,000 points & or & & $\begin{array}{l}\text { Buy the lottery ticket for } 10,000 \text { points and } \\
\text { keep the remaining } 0 \text { points }\end{array}$ \\
\hline Keep 10,000 points & or & $\square$ & $\begin{array}{l}\text { Buy the lottery ticket for } 9,000 \text { points and } \\
\text { keep the remaining } 1,000 \text { points }\end{array}$ \\
\hline Keep 10,000 points & or & c & $\begin{array}{l}\text { Buy the lottery ticket for } 8,000 \text { points and } \\
\text { keep the remaining } 2,000 \text { points }\end{array}$ \\
\hline Keep 10,000 points & or & t & $\begin{array}{l}\text { Buy the lottery ticket for } 7,000 \text { points and } \\
\text { keep the remaining } 3,000 \text { points }\end{array}$ \\
\hline Keep 10,000 points & or & c & $\begin{array}{l}\text { Buy the lottery ticket for } 6,000 \text { points and } \\
\text { keep the remaining } 4,000 \text { points }\end{array}$ \\
\hline Keep 10,000 points & or & - & $\begin{array}{l}\text { Buy the lottery ticket for } 5,500 \text { points and } \\
\text { keep the remaining } 4,500 \text { points }\end{array}$ \\
\hline Keep 10,000 points & or & r & $\begin{array}{l}\text { Buy the lottery ticket for } 5,250 \text { points and } \\
\text { keep the remaining } 4,750 \text { points }\end{array}$ \\
\hline Keep 10,000 points & or & & $\begin{array}{l}\text { Buy the lottery ticket for } 5,000 \text { points and } \\
\text { keep the remaining } 5,000 \text { points }\end{array}$ \\
\hline Keep 10,000 points & or & is & $\begin{array}{l}\text { Buy the lottery ticket for } 4,750 \text { points and } \\
\text { keep the remaining } 5,250 \text { points }\end{array}$ \\
\hline Keep 10,000 points & or & C & $\begin{array}{l}\text { Buy the lottery ticket for } 4,500 \text { points and } \\
\text { keep the remaining } 5,500 \text { points }\end{array}$ \\
\hline Keep 10,000 points & or & & $\begin{array}{l}\text { Buy the lottery ticket for } 4,250 \text { points and } \\
\text { keep the remaining } 5,750 \text { points }\end{array}$ \\
\hline Keep 10,000 points & or & r & $\begin{array}{l}\text { Buy the lottery ticket for } 4,000 \text { points and } \\
\text { keep the remaining } 6,000 \text { points }\end{array}$ \\
\hline Keep 10,000 points & or & ( & $\begin{array}{l}\text { Buy the lottery ticket for } 3,750 \text { points and } \\
\text { keep the remaining } 6,250 \text { points }\end{array}$ \\
\hline Keep 10,000 points & or & & $\begin{array}{l}\text { Buy the lottery ticket for } 3,500 \text { points and } \\
\text { keep the remaining } 6,500 \text { points }\end{array}$ \\
\hline Keep 10,000 points & or & {[} & $\begin{array}{l}\text { Buy the lottery ticket for } 3,250 \text { points and } \\
\text { keep the remaining } 6,750 \text { points }\end{array}$ \\
\hline Keep 10,000 points & or & c & $\begin{array}{l}\text { Buy the lottery ticket for } 3,000 \text { points and } \\
\text { keep the remaining } 7,000 \text { points }\end{array}$ \\
\hline Keep 10,000 points & or & E & $\begin{array}{l}\text { Buy the lottery ticket for } 2,500 \text { points and } \\
\text { keep the remaining } 7,500 \text { points }\end{array}$ \\
\hline Keep 10,000 points & or & & Buy the lottery ticket for 2,000 points and \\
\hline
\end{tabular}

Examining the screenshots above shows that if a user always clicked, say, the third from 
Figure D.4: WTP, Lottery 2.

\section{YouGov}

For this question, you have been given 9,000 points. You will be offered the opportunity to exchange some of these points for a lottery ticket. This lottery ticket has a $\mathbf{5 0} \%$ chance of paying you $\mathbf{8 , 0 0 0}$ points, and a $\mathbf{5 0 \%}$ chance of paying $\mathbf{2 , 0 0 0}$ points.

For example, if you choose to pay 3,000 points for a lottery ticket, and this question is chosen for payment, you will:

- Pay 3,000 points for the lottery ticket

- Keep 6,000 points for yourself

- Earn whatever proceeds you get from the lottery ticket (if any)

For each row in the table below, which option would you prefer?

\begin{tabular}{|c|c|c|c|}
\hline Keep 9,000 points & or & & $\begin{array}{l}\text { Buy the lottery ticket for } 9,000 \text { points and } \\
\text { keep the remaining } 0 \text { points }\end{array}$ \\
\hline Keep 9,000 points & or & $\square$ & $\begin{array}{l}\text { Buy the lottery ticket for } 8,000 \text { points and } \\
\text { keep the remaining } 1,000 \text { points }\end{array}$ \\
\hline Keep 9,000 points & or & $\square$ & $\begin{array}{l}\text { Buy the lottery ticket for } 7,000 \text { points and } \\
\text { keep the remaining } 2,000 \text { points }\end{array}$ \\
\hline Keep 9,000 points & or & $\pi$ & $\begin{array}{l}\text { Buy the lottery ticket for } 6,000 \text { points and } \\
\text { keep the remaining } 3,000 \text { points }\end{array}$ \\
\hline Keep 9,000 points & or & 10 & $\begin{array}{l}\text { Buy the lottery ticket for } 5,500 \text { points and } \\
\text { keep the remaining } 3,500 \text { points }\end{array}$ \\
\hline Keep 9,000 points & or &  & $\begin{array}{l}\text { Buy the lottery ticket for } 5,250 \text { points and } \\
\text { keep the remaining } 3,750 \text { points }\end{array}$ \\
\hline Keep 9,000 points & or & [i] & $\begin{array}{l}\text { Buy the lottery ticket for } 5,000 \text { points and } \\
\text { keep the remaining } 4,000 \text { points }\end{array}$ \\
\hline Keep 9,000 points & or & 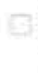 & $\begin{array}{l}\text { Buy the lottery ticket for } 4,750 \text { points and } \\
\text { keep the remaining } 4,250 \text { points }\end{array}$ \\
\hline Keep 9,000 points & or & 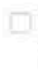 & $\begin{array}{l}\text { Buy the lottery ticket for } 4,500 \text { points and } \\
\text { keep the remaining } 4,500 \text { points }\end{array}$ \\
\hline Keep 9,000 points & or & - & $\begin{array}{l}\text { Buy the lottery ticket for } 4,250 \text { points and } \\
\text { keep the remaining } 4,750 \text { points }\end{array}$ \\
\hline Keep 9,000 points & or & $\square$ & $\begin{array}{l}\text { Buy the lottery ticket for } 4,000 \text { points and } \\
\text { keep the remaining } 5,000 \text { points }\end{array}$ \\
\hline Keep 9,000 points & or & $m$ & $\begin{array}{l}\text { Buy the lottery ticket for } 3,750 \text { points and } \\
\text { keep the remaining } 5,250 \text { points }\end{array}$ \\
\hline Keep 9,000 points & or & $\pi$ & $\begin{array}{l}\text { Buy the lottery ticket for } 3,500 \text { points and } \\
\text { keep the remaining } 5,500 \text { points }\end{array}$ \\
\hline Keep 9,000 points & or & $(7)$ & $\begin{array}{l}\text { Buy the lottery ticket for } 3,250 \text { points and } \\
\text { keep the remaining } 5,750 \text { points }\end{array}$ \\
\hline Keep 9,000 points & or & $\square$ & $\begin{array}{l}\text { Buy the lottery ticket for } 3,000 \text { points and } \\
\text { keep the remaining } 6,000 \text { points }\end{array}$ \\
\hline Keep 9,000 points & or & $\square$ & $\begin{array}{l}\text { Buy the lottery ticket for } 2,500 \text { points and } \\
\text { keep the remaining } 6,500 \text { points }\end{array}$ \\
\hline Keep 9,000 points & or & $\square$ & $\begin{array}{l}\text { Buy the lottery ticket for } 2,000 \text { points and } \\
\text { keep the remaining } 7,000 \text { points }\end{array}$ \\
\hline Keep 9,000 points & or & $\checkmark$ & Buy the lottery ticket for 1,500 points and \\
\hline
\end{tabular}


the top box in each MPL it would induce a negative correlation between WTA/P. This is not a particular concern due to the fact that results are robust to excluding those that give extreme answers, as these people are the most likely to follow such a pattern. However, here we conduct more extensive checks that control explicitly for the average position a respondent chooses on non-risk related MPLs, including analyzing the data of an additional large scale study that reversed the order of the MPL for WTP.

In particular, as the questions about WTA and WTP are far apart in the survey, any issue caused by people picking different points on an MPL would be more likely due to a tendency, rather than an explicit position chosen on each MPL. Thus, if we control for such a tendency, this should get rid of spurious correlation (or lack thereof) created by the ordering of the MPLs. To do so, we need a measure of this tendency. This is easily obtained from the other MPLs in our studies, especially Study 2, which contains a number of MPLs that measure something other than risk attitudes $1^{1}$ We use, as a control for this tendency, the location of the switching point on six MPLs unrelated to risk in Study 2: two regarding time preference, and four regarding social preferences (two in the advantageous domain and two in the disadvantageous domain). For each of these MPLs we identify the first row in which the respondent clicked the right hand side the MPL (if individuals never switched they are assigned a value of the last row number plus one).

We control for a general tendency to select answers in higher or lower spots on an MPL in several ways in Table D.1. All columns examine the correlation between the Average WTA and Average WTP measures from Study 2 (where we have the most controls for MPL position). The first column shows the unconditional correlation from a standardized regression. The next four columns enter information about other choices in various ways. The second column includes the first three principal components of the switching rows. The first principal component is essentially an average, and the others contain more information

\footnotetext{
${ }^{1}$ Risk measures are correlated with WTA and WTP for lotteries - see Section 6. Thus, including the MPL positions on those measures would add error to the average position variables, as some of the variation in that variable will represent real correlations between risk measures and WTA / WTP.
} 
about choices in these other MPLs. Together, the first three principal components capturing $85 \%$ of the variation in MPL switching point location. The third column breaks each of these three components into deciles, and then enters a dummy variable for each decile. This is 30 dummy variables in all. The fourth column breaks the first principal component into 100 percentile bins, and enters a dummy for each. Both of these allow for a more non-parametric dependence of the correlation on average choice. The final column enters a dummy variable for each possible switching position in each of the six MPLs. Across all columns and both panels the pattern is clear: the partial correlation barely moves no matter how we try to control for the average position a respondent takes on other MPLs.

We can look at this issue one other way. Those that are most wedded to a given position on the MPL will have a lower standard deviation of switching points. If switching points are just random, with a person-specific parameter deciding where on the MPL they chose to switch, then we should see a positive relationship between the standard deviation of switching points and the correlation between WTA and WTP.

Figure D.5 shows the correlation between WTA and WTP as a function of the standard deviation of MPL switching points. To produce the figure, we generate a variable for person $i$ that describes their contribution to the correlation in their percentile $p$ as

$$
\frac{\left(\mathrm{WTA}_{i}-{\overline{\mathrm{WTA}_{p}}}\right)\left(\mathrm{WTP}_{i}-\overline{\mathrm{WTP}}_{p}\right)}{\left(\operatorname{Var}\left[\mathrm{WTA}_{p}\right] \operatorname{Var}\left[\mathrm{WTP}_{p}\right]\right)^{\frac{1}{2}}}
$$

This can then be plotted, non-parametrically, versus the percentile of the standard deviation. The black lines indicate the non-parametric plot, and the grey bar indicates the $95 \%$ confidence intervals.

The first panel of Figure D.5 does not smooth the correlations across percentiles. As such, there does not seem to be an apparent pattern. Therefore, in the second panel, we smooth the non-parametric plot. As can be seen, those that have very little variation in their MPL switching point do, indeed, exhibit a negative correlation between WTA and 
Table D.1: Partial correlations controlling for average MPL switching position on non-risk questions.

\begin{tabular}{|c|c|c|c|c|c|}
\hline \multicolumn{6}{|c|}{ Dependent Variable: Average WTP } \\
\hline Average WTA & $\begin{array}{l}-0.09 \\
(.057)\end{array}$ & $\begin{array}{l}-0.04 \\
(.052)\end{array}$ & $\begin{array}{l}-0.04 \\
(.047)\end{array}$ & $\begin{array}{l}-0.05 \\
(.046)\end{array}$ & $\begin{array}{l}-0.05 \\
(.037)\end{array}$ \\
\hline $\begin{array}{l}\text { Three Principal } \\
\text { Components }\end{array}$ & & $\mathrm{Y}$ & & & \\
\hline $\begin{array}{l}\text { Deciles of First } 3 \\
\text { Principal Components }\end{array}$ & & & $\mathrm{Y}$ & & \\
\hline $\begin{array}{l}\text { Percentiles of First } \\
\text { Principal Component }\end{array}$ & & & & $\mathrm{Y}$ & \\
\hline $\begin{array}{l}\text { Indicators for Switching } \\
\text { Point in six Questions }\end{array}$ & & & & & $\mathrm{Y}$ \\
\hline \multicolumn{6}{|c|}{ Dependent Variable: Average WTA } \\
\hline Average WTP & $\begin{array}{l}-0.09 \\
(.059)\end{array}$ & $\begin{array}{l}-0.04 \\
(.056)\end{array}$ & $\begin{array}{l}-0.05 \\
(.051)\end{array}$ & $\begin{array}{l}-0.06 \\
(.049)\end{array}$ & $\begin{array}{l}-0.05 \\
(.040)\end{array}$ \\
\hline $\begin{array}{l}\text { Three Principal } \\
\text { Components }\end{array}$ & & $\mathrm{Y}$ & & & \\
\hline $\begin{array}{l}\text { Deciles of First } 3 \\
\text { Principal Components }\end{array}$ & & & $\mathrm{Y}$ & & \\
\hline $\begin{array}{l}\text { Percentiles of First } \\
\text { Principal Component }\end{array}$ & & & & $\mathrm{Y}$ & \\
\hline $\begin{array}{l}\text { Indicators for Switching } \\
\text { Point in six Questions }\end{array}$ & & & & & $\mathrm{Y}$ \\
\hline
\end{tabular}

Notes: ${ }^{* * *},{ }^{* *},{ }^{*}$ denote statistical significance at the $1 \%, 5 \%$, and $10 \%$ level, with standard errors in parentheses.

WTP. However, above the 25th percentile, there is a non-monotonic relationship between the correlation of WTA/WTP and the standard deviation of MPL switching points. Indeed, the non-parametric curve never exceeds 0.07 , and the $95 \%$ confidence interval never exceeds 0.2. The average correlation above the 25th percentile is 0.00 . Thus, any effect of MPL ordering on our results is likely to be quite small.

As a final test, as part of another study, a subset of the coauthors experimentally varied whether or not WTP was elicited using the standard ordering, featured throughout this 
Figure D.5: Correlation as a function of standard deviation of switching points.



Percentile of Standard Deviation of MPL Switching Points

paper, or the opposite ordering. This study was administered to a non-representative subset of the British population (Carvalho et al., 2017). Analysis of this data, in the style of Table 2 , is shown in Table D.2.

There are a number of salient features of the data. First, the correlations using the standard ordering are about 0.1 to 0.15 higher than found in our study. As discussed in Section 5, this difference is likely due to a different population being studied. Second, using 
Table D.2: Reversing the order of the WTP MPL.

\begin{tabular}{|c|c|c|c|c|c|c|c|}
\hline & \multirow[b]{2}{*}{$\mathrm{N}$} & \multicolumn{4}{|c|}{ Correlation between WTA and WTP } & \multicolumn{2}{|c|}{$\begin{array}{c}\text { Correlation within } \\
\text { Type }\end{array}$} \\
\hline & & Lottery 1 & Lottery 2 & Averages & ORIV & WTA & WTP \\
\hline $\begin{array}{l}\text { Standard } \\
\text { Order }\end{array}$ & 1,037 & $\begin{array}{c}0.05 \\
(.035)\end{array}$ & $\begin{array}{c}0.03 \\
(.038)\end{array}$ & $\begin{array}{c}0.05 \\
(.036)\end{array}$ & $\begin{array}{l}0.06 \\
(.044)\end{array}$ & $\begin{array}{c}0.69^{* * *} \\
(.030)\end{array}$ & $\begin{array}{l}0.72^{* * *} \\
(.031)\end{array}$ \\
\hline $\begin{array}{l}\text { Reverse, } \\
\text { Order (WTP) }\end{array}$ & 953 & $\begin{array}{l}0.15^{* * *} \\
(.039)\end{array}$ & $\begin{array}{l}0.18^{* * *} \\
(.039)\end{array}$ & $\begin{array}{l}0.18^{* * *} \\
(.037)\end{array}$ & $\begin{array}{l}0.22^{* * *} \\
(.046)\end{array}$ & $\begin{array}{l}0.74^{* * *} \\
(.029)\end{array}$ & $\begin{array}{l}0.64^{* * *} \\
(.041)\end{array}$ \\
\hline All Data & 1,990 & $\begin{array}{l}0.10^{* * *} \\
(.027)\end{array}$ & $\begin{array}{l}0.10^{* * *} \\
(.027)\end{array}$ & $\begin{array}{l}0.11^{* * *} \\
(.026)\end{array}$ & $\begin{array}{c}0.13^{* * *} \\
(.031)\end{array}$ & $\begin{array}{l}0.71^{* * *} \\
(.021)\end{array}$ & $\begin{array}{l}0.69^{* * *} \\
(.025)\end{array}$ \\
\hline
\end{tabular}

Notes: ${ }^{* *},{ }^{* *},{ }^{*}$ denote statistical significance at the $1 \%, 5 \%$, and $10 \%$ level, with bootstrapped standard errors from 10,000 simulations in parentheses.

the alternate ordering increases correlations by 0.1 to 0.15 . Finally, as there does not seem to be a "correct" ordering for these MPLs, the row gives what is essentially an average of the first two rows. A final point worth noting is the distribution of endowment effects is virtually unchanged by reversing the order of the WTP MPL. Thus, had we altered the ordering of the WTP MPL in our studies, it is likely that the correlation we observed would be much closer to zero, while other results would remain virtually unchanged.

However, the effect of reversing the MPL order seems to not just change answers, it seems to change the composition of the people completing the survey. Although each ordering was administered to $50 \%$ of the sample population, about $10 \%$ fewer people completed the alternate version. This seems to be because people found the alternate version so confusing they dropped out of the study altogether. An additional piece of evidence is the much lower correlation between WTP measures when using the alternative ordering. This suggests that an increase of 0.15 in the correlations due to changing the order of the MPL is an upper bound, as some of this change is likely due to a change in the composition of the people completing the survey. 